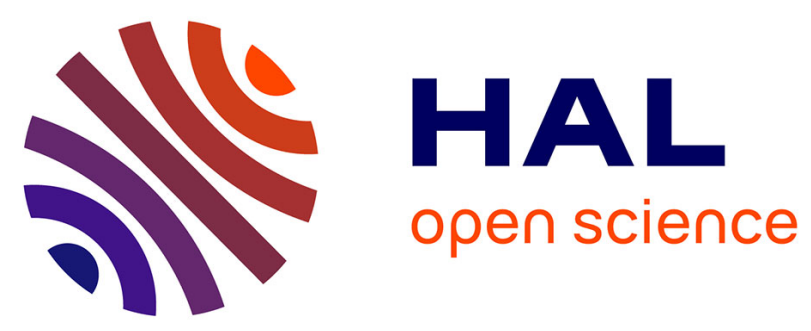

\title{
Segregation Analysis of Blood Oxygen Saturation in Broilers Suggests a Major Gene Influence on Ascites
}

Pau Navarro, Peter Visscher, Alfons Koerhuis, Dimitrios Chatziplis, Chris Haley

\section{- To cite this version:}

Pau Navarro, Peter Visscher, Alfons Koerhuis, Dimitrios Chatziplis, Chris Haley. Segregation Analysis of Blood Oxygen Saturation in Broilers Suggests a Major Gene Influence on Ascites. British Poultry Science, 2007, 47 (06), pp.671-684. 10.1080/00071660601077931 . hal-00545306

\author{
HAL Id: hal-00545306 \\ https://hal.science/hal-00545306
}

Submitted on 10 Dec 2010

HAL is a multi-disciplinary open access archive for the deposit and dissemination of scientific research documents, whether they are published or not. The documents may come from teaching and research institutions in France or abroad, or from public or private research centers.
L'archive ouverte pluridisciplinaire HAL, est destinée au dépôt et à la diffusion de documents scientifiques de niveau recherche, publiés ou non, émanant des établissements d'enseignement et de recherche français ou étrangers, des laboratoires publics ou privés. 


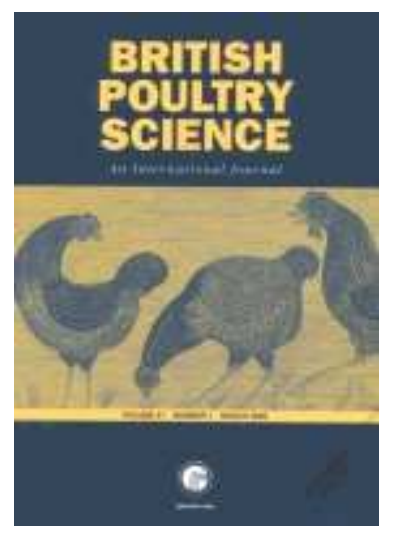

\section{Segregation Analysis of Blood Oxygen Saturation in Broilers Suggests a Major Gene Influence on Ascites}

\begin{tabular}{|r|l|}
\hline Journal: & British Poultry Science \\
\hline Manuscript ID: & CBPS-2005-020.R1 \\
\hline Manuscript Type: & Original Manuscript \\
\hline Author: & 15-Mar-2006 \\
\hline & $\begin{array}{l}\text { Complete List of Authors: } \\
\text { Kiology } \\
\text { Koerhuis, Alfons } \\
\text { Chatziplis, Dimitrios } \\
\text { Haley, Chris; Roslin Institute, Division of Genetics and Genomics }\end{array}$ \\
\hline Keywords: & Ascites, Broilers, Genetics \\
\hline
\end{tabular}

\section{scholarONE" \\ Manuscript Central}




\section{Segregation Analysis of Blood Oxygen Saturation in Broilers Suggests a Major}

1

P. NAVARRO ${ }^{*, 1,2}$, P. M. VISSCHER ${ }^{\dagger}$, D. CHATZIPLIS ${ }^{\ddagger}$, A. N. M. KOERHUIS ${ }^{\ddagger}$ AND

\section{S. HALEY*}

${ }^{*}$ Roslin Institute, Roslin, Midlothian EH25 9PS, Scotland (UK)

${ }^{\dagger}$ Institute of Evolutionary Biology, University of Edinburgh, West Mains Road,

Edinburgh EH9 3JT, Scotland (UK)

† Aviagen Ltd., Newbridge, Midlothian, EH28 8SZ, Scotland (UK)

Corresponding author: Pau Navarro, Institute of Evolutionary Biology, University of

Edinburgh, West Mains Road, Edinburgh EH9 3JT, Scotland (UK).

Tel: +44 (0) 1316505442

Fax: $+44(0) 1316506564$

E-mail: Pau.Navarro@ed.ac.uk

\section{SHORT TITLE: SEGREGATION ANALYSIS BLOOD OXYGEN SATURATION}

ABBREVIATION KEY: $\mathrm{a}$ = additive effect; $\mathrm{d}$ = dominance effect; Flesh = fleshing score; $\mathrm{MCMC}=$ Markov Chain Monte Carlo; $\mathrm{p}_{\mathrm{b}}=$ frequency of the $\mathrm{b}$ allele; $\mathrm{p}_{\mathrm{B}}=$ frequency of the $\mathrm{B}$ allele; $\mathrm{p}_{\mathrm{bb}}=$ frequency of the $\mathrm{bb}$ genotype; $\mathrm{p}_{\mathrm{Bb}}=$ frequency of the $\mathrm{Bb}$ genotype; $\mathrm{p}_{\mathrm{BB}}=$ frequency of the BB genotype; REML = restricted maximum likelihood; RN = Napole yield; $\mathrm{SaO}=$ blood oxygen saturation; Weight $=$ body weight $; \sigma_{\mathrm{e}}{ }^{2}=$ residual variance; $\sigma_{\mathrm{m}}{ }^{2}=$ major locus variance; $\sigma_{\mathrm{p}}{ }^{2}=$ phenotypic variance; $\sigma_{\mathrm{u}}{ }^{2}=$ polygenic variance

\section{SECTION: GENETICS}

(Key words: ascites, blood oxygen saturation, broiler, major gene, production) 
$28{ }^{1}$ Present address: Pau Navarro, Institute of Evolutionary Biology, University of

29 Edinburgh, West Mains Road, Edinburgh EH9 3JT, Scotland (UK).

30

${ }^{2}$ To whom correspondence should be addressed: Pau.Navarro@ed.ac.uk. 
Abstract 1. Blood oxygen saturation $(\mathrm{SaO})$ is a potential indicator trait for resistance to ascites in chickens.

2. The objective of the study was to investigate the genetic architecture of $\mathrm{SaO}$ in a meat-type chicken line reared in commercial conditions.

3. Data were collected over 15 generations of selection and were divided into two data sets on the basis of a change in recording age from six to five weeks of age approximately halfway through the period. The resulting pedigrees comprised in excess of 90,000 birds each and, on average, $12 \%$ of these birds had $\mathrm{SaO}$ records.

4. Segregation analyses of $\mathrm{SaO}$ were carried out assuming a mixed inheritance model that included a major locus segregating in a polygenic background.

5. The analyses suggest that a major gene is involved in the genetic control of $\mathrm{SaO}$ in this line. The putative gene acts in a dominant fashion and has an additive effect of around 0.90 $\sigma_{\mathrm{p}}$, equivalent to a predicted difference in $\mathrm{SaO}$ between the two homozygous classes of more than $10 \%$. The frequency of the allele that increases $\mathrm{SaO}$ changed from 0.53 to 0.65 from the first to the second set of data, consistent with selection on $\mathrm{SaO}$ scores.

6. Using estimated genotype probabilities at the putative major locus, we inferred that it acts in an overdominant fashion on body weight and fleshing score. If the low $\mathrm{SaO}$ allele leads to a susceptibility to ascites, its combined effects are consistent with it being maintained in the population by a balance of natural selection on fitness and artificial selection on growth and carcass traits.

7. Even with selection on both $\mathrm{SaO}$ and growth traits, the combined genotypic effects would make it difficult to remove the unfavourable low-SaO allele by means of traditional selection without the use of genetic markers. 


\section{INTRODUCTION}

Blood oxygen saturation $(\mathrm{SaO})$ is a potential indicator trait for resistance to ascites in chickens (Wideman et al., 1998). In a previous study (Navarro et al., 2006), we presented heritabilities of $\mathrm{SaO}$, body weight (Weight) and fleshing score (Flesh, a measure of breast conformation), and genetic correlations between these traits for four meat-type chicken lines.

We showed that $\mathrm{SaO}$ was moderately heritable (heritabilities for this trait ranged from 0.1 to 0.2 ) and that its genetic correlation with production traits was low, so that simultaneous selection for increased $\mathrm{SaO}$ and increased production should be possible. These genetic parameters were obtained assuming an infinitesimal model (Fisher, 1918), which assumes that the (quantitative) trait was influenced by an infinite number of unlinked loci (polygenes), each with an infinitely small additive effect on the trait. However, in recent years, several studies have shown that one or few genes, or quantitative trait loci (QTL), explain an important amount of the phenotypic or genetic variation for some quantitative traits. Today, examples of genes or QTL with large effect on quantitative traits of agricultural interest are numerous. For example, the RN-mutation in pigs (Milan et al., 2000) affecting meat quality, the Booroola gene (Piper and Bindon, 1982) in sheep affecting ovulation rate and the double muscling gene (Hanset and Michaux, 1985a; Hanset and Michaux, 1985b) in cattle.

Several of the known major genes in livestock were first inferred from their effects on segregation of phenotypes within pedigrees. Although simple metrics can provide evidence for major gene segregation, fullest use of available data is made in the context of an appropriate analytical model. Mixed inheritance models were first introduced in human genetics to discriminate between modes of inheritance and particularly to infer the presence of major genes (Elston and Stewart, 1971; Morton and Maclean, 1974). These methods were first used within a maximum likelihood framework, which restricted their practical use to the analysis of small pedigrees. Although a series of approximations of the mixed inheritance model likelihood are available for animal breeding populations with simple structures (see, for example, Knott et al. (1992)), analysis of large complex pedigrees (like the ones usually encountered in animal breeding) is only feasible when sampling based techniques are used either to estimate 
likelihoods (Guo and Thompson, 1991; Guo and Thompson, 1994) or to implement Bayesian analysis (Janss et al., 1995).

Markov Chain Monte Carlo (MCMC) sampling methods provide an efficient means to carry out these tasks. In particular the Gibbs Sampler, an MCMC method, is now widely used in genetic analyses. It is capable of generating samples from the joint distribution (usually complex) of several random variables by sampling from known and simple conditional distributions. From these samples, marginal distributions of each variable can be obtained and provide estimates of the posterior distributions of the model parameters.

Little is known about the genetics underlying ascites-related traits. Here, we investigate the genetic architecture of $\mathrm{SaO}$ using segregation analysis. Data come from the line for which we obtained the highest estimates of genetic variance and heritability for $\mathrm{SaO}$ in our previous analyses (Navarro et al., 2006). This line shows a slightly higher ascites-related mortality than other Aviagen Ltd. lines (A. Koerhuis, personal communication) and it is the heaviest of the lines studied. We study the possible existence of a major gene or quantitative trait locus (QTL) involved in the control of $\mathrm{SaO}$. To this end, we have carried our analyses assuming a mixed inheritance model that includes a major locus as well as polygenes. In subsequent analyses, we have used the estimated genotype probabilities at the putative major locus to investigate its effect on body weight and fleshing score. The results obtained are consistent with the segregation of a major gene and help reconcile observations on the genetic correlations between traits, the incidence of ascites and its relationship with selection on growth and carcass traits.

\section{MATERIALS AND METHODS}

Data

Two data sets (data sets 1 and 2) that each consisted of around eight overlapping generations of selection were available from a meat-type chicken population. The population studied is a male line that has been closed for between 30 to 40 generations and has a history of $\underline{\text { selection on wheat diets. Selection has been more focused on growth rate and efficiency and less }}$ emphasis has been placed on yield. In addition the population has been exposed to considerable 
family selection against broiler mortality and leg defects. Both data sets contained records of $\mathrm{SaO}$, body weight (Weight) and fleshing score (Flesh, a measure of breast conformation $)_{4} \mathrm{SaO}$ was directly measured using a pulse oximeter. A sensor was attached to a Criticare Pulse Oximeter 504US ${ }^{1}$ and positioned on the wing to illuminate the tissue between the radius and ulna for measurement of percentage saturation of haemoglobin with oxygen (Julian and Mirsalimi, 1992). When the bird was settled, two readings were taken, and the record for this bird was taken to be an average of both readings. Fleshing is a conformation score with higher scores relating to superior breast muscle development relative to the size of the whole bird. Recording is carried out in handheld terminals grading the birds between 1 and 5, 1 being the birds with the least breast meat and 5 the most. Feel of the breast breadth and depth and length of the keel are also taken into account. $\mathrm{SaO}$ data were only available for male selection candidates whereas Weight and Flesh were recorded on most birds. Records were taken at six weeks of age for data set 1 . Data set 2 consisted of data from the same line immediately following a shift of the recording age from six to five weeks of age.

A description of the pedigree and data structure for the data sets used is presented in Table 1. For both data sets, the mean number of birds with $\mathrm{SaO}$ record per full-sib family was less than five (with a minimum value of one and a maximum value of 25) and the mean paternal half-sib family size was less than 30 (with a minimum value of one and a maximum value of 106).

\section{[TABLE 1],}

\section{Statistical Analyses}

Segregation analyses to assess the possibility that a locus with large effect was involved in the genetic control of $\mathrm{SaO}$ were performed on data sets 1 and 2. Since results from more recent data are of greatest interest if follow up studies were to be carried out or our findings

\footnotetext{
${ }^{1}$ Criticare Systems Inc., Milwaukee, U.S.A, supplied by R.L. Dolby, Stirling, UK
} 
134 | were to have an impact on breeding programme decisions, a more comprehensive set of
135

136

137 analyses was done on data set 2. Details of the analyses methods are presented as an annex.

In brief, a mixed inheritance model was used for the segregation analysis. Mixed inheritance models are a combination of infinitesimal and finite gene models. In our analyses, a single major locus was modelled in addition to a polygenic effect. The major locus was assumed to be autosomal and biallelic with Mendelian transmission probabilities and with an additive (a) and a dominance effect (d). The genotypic value for birds with genotype BB at the major locus is a, - $\mathrm{a}$ for bb birds and $\mathrm{d}$ for $\mathrm{Bb}$ birds. The major locus was assumed to be in Hardy-Weinberg equilibrium proportions in the "base generation" (i.e., the first generation of a data set).

These analyses provide as output distributions of the parameters estimated and the mean and the standard deviation of these distributions can be used as estimates of the parameters and their standard error. In this case, we obtained estimates of major locus effects and allelic frequencies, polygenic and residual variances, as well as genotypic probabilities for each bird.

Major locus effects and frequencies are used to estimate the variance explained by the major locus, and this is then used to assess if it is likely that a major locus is indeed segregating for $\underline{\mathrm{SaO}}$.

We also carried out some exploratory analyses on genotype probabilities estimated for sires and selection candidates from data set 2 , and investigated the effect of the putative major locus on body weight and fleshing score.

\section{RESULTS}

\section{Data}

Table 2 shows descriptive statistics of the distributions of $\mathrm{SaO}$, Weight and Flesh. Means and standard deviations were obtained with GENSTAT (GENSTAT 5 COMMITTEE, 1993). Skewness and kurtosis coefficients were obtained with MINITAB 12 (MINITAB Inc., 1998). Whilst mean body weight for data set 1 was $20 \%$ higher than mean data set 2 body weight, differences were smaller for mean $\mathrm{SaO}$ and Flesh (respectively, 2\% lower and 2\% higher for data taken at six weeks in the less recent pedigree). Coefficients of variation were similar within traits across data sets. $\mathrm{SaO}$ distributions (adjusted for fixed effects or unadjusted)
Deleted: Segregation Analysis. A Formatted: Font: Not Bold, Not Italic

Deleted: The mixed model equation that describes the model fitted to the data is:पI

$\mathbf{y}=\mathbf{X b}+\mathbf{Z u}+\mathbf{Z W} \mathbf{m}+\mathbf{e}$

[1]पा

where $\mathbf{y}$ is the vector of phenotypic

observations, $\mathbf{b}$ is the vector of fixed nongenetic effects and $\mathbf{X}$ is the design matrix relating fixed non-genetic effects to observations. $\mathbf{Z}$ is the incidence matrix for random polygenic effects $(\mathbf{u} \sim \mathrm{N}(0$, $\left.\mathbf{A} \boldsymbol{\sigma}_{u}{ }^{2}\right)$-where $\mathbf{A}$ is the numerator $\left.\mathbf{A} \sigma_{u}{ }_{u}\right)$-where $\mathbf{A}$ is the numerator
relationship matrix and $\sigma_{u}{ }^{2}$ is the

polygenic variance)- and single locus effects. $\mathbf{W}$ is a three column matrix that contains information on the genotype of each individual and $\mathbf{m}$ is the vector of major-genotype means $\left(\mathbf{m}^{\prime}=[-\mathrm{a}, \mathrm{d}, \mathrm{a}]\right)$, hence $\mathbf{W m}$ is the vector of random effects at the single locus. $\mathbf{e}\left(\sim \mathrm{N}\left(0, \mathbf{I} \sigma_{\mathrm{e}}^{2}\right)\right)$ is a vector of random errors. II

Janss et al. (1995) proposed an efficient scheme using the Gibbs sampler for the study of mixed inheritance models in animal populations. In our analyses, carried out with software developed at Roslin Institute by Ricardo Pong-Wong (Walling et al., 2002), we used the sampling scheme they described (see Janss et al. (1995) and Janss et al. (1997) for details) to obtain marginal posterior distributions for the major locus parameters (frequency and additive and dominance effect), population mean and polygenic and residual variances. For each iteration of the Gibbs sampler, every bird was assigned a genotype. Averaging over all retained iterations provides major locus genotype probabilities $\left(\mathrm{p}_{\mathrm{BB}}, \mathrm{p}_{\mathrm{Bb}}\right.$ and $\mathrm{p}_{\mathrm{bb}}$ ) for each bird in the pedigree.II The variance explained by the major locus $\left(\sigma_{\mathrm{m}}^{2}\right)$ is defined as:

$\sigma_{\mathrm{m}}{ }^{2}=2 \mathrm{p}_{\mathrm{B}}\left(1-\mathrm{p}_{\mathrm{B}}\right)\left[\mathrm{a}+\mathrm{d}\left(\left(1-\mathrm{p}_{\mathrm{B}}\right)-\mathrm{p}_{\mathrm{B}}\right)\right]^{2}+$ $\left[2 \mathrm{p}_{\mathrm{B}}\left(1-\mathrm{p}_{\mathrm{B}}\right) \mathrm{d}\right]^{2}$

(Falconer and Mackay, 1996) and was computed from the major locus genotypic effects and allele frequency sampled at each iteration. Likewise, we calculated the degree of dominance as d/a.II We used non-informative prior distributions, uniform on $(-\infty ;+\infty)$ for fixed non-genetic effects and d, on [ 0 ; $+\infty)$ for a and on $[0 ; 1]$ for major allele $B$ frequency. We used an inverse-gamma prior distribution on $(0 ;+\infty)$ for variances with a flat prior for $\log$ (variance). This type of prior distribution for variances should cause the mean of the marginal posterior distributions to tend towards zero if the data available do not support varia ... [1]

Deleted: A description of the pedigree and data structure for the data sets used is presented in Table 1. For both data sets, the mean number of birds with $\mathrm{SaO}$ record per full-sib family was less than five (with a minimum value of one and a maximum value of 25) and the mean paternal half-sib family size was less than 30 (with a minimum value of one and a maximum value of 106). 
showed skewness coefficients that were more extreme than -0.70 for both data sets. Adjusting raw data for fixed effects slightly decreased absolute skewness but increased kurtosis (making the distribution more leptokurtic), more markedly so for data set 1.
165

\section{[TABLE 2]}

Table 3 shows REML estimates of heritabilities and genetic correlations (and standard errors) for $\mathrm{SaO}$, Weight and Flesh obtained from trivariate analyses for data sets 1 and 2 when fitting a purely polygenic model. The estimated heritability for $\mathrm{SaO}$ from data set 1 was higher than that from data set 2 . This was due to a $43 \%$ decrease in $\sigma_{u}{ }^{2}$ (that changed from 14.37 to 8.18) accompanied by a smaller $(16 \%)$ decrease in $\sigma_{\mathrm{e}}{ }^{2}$ (that changed from 54.06 to 45.18 ). Genetic correlations between $\mathrm{SaO}$ and Weight and Flesh were negative but not significantly different from $0(\mathrm{P}>0.05)$ for either data set.

[TABLE 3]

\section{Segregation Analyses}

Figure 1 shows the pooled posterior distributions of $\sigma_{\underline{\underline{u}}}{ }^{2} \sigma_{\underline{\underline{m}}}{ }^{2}$ and $\sigma_{\underline{e}}{ }^{2}$ for data sets 1 and 2. Following the criteria detailed in the annex (i.e. the major locus variance distributions presented zero densities for values equal to zero) we inferred that a major locus involved in the control of $\mathrm{SaO}$ was segregating in the population studied. Table 4 shows estimates and standard deviations of the major locus additive and dominance effects, B allele frequency and residual, polygenic and major locus variances as well as polygenic and major locus heritabilities and dominance deviance The dominance deviance was very close to 1 for both data sets $(1.12 \pm 0.06$ and $1.02 \pm 0.06$ respectively) and therefore we will assume in the following that a and $\mathrm{d}$ can be considered equal, so that the locus acts in a dominant fashion, For data set $1 \mathrm{a}=\mathrm{d}=7.2 \% \mathrm{SaO}$ which means that the difference between bb birds and $\mathrm{BB}$ or $\mathrm{Bb}$ birds in $\mathrm{SaO}$ would be around $14 \%$. The standardized locus additive effect was $0.80 \sigma_{\mathrm{p}}\left(\right.$ or $1.12 \sqrt{ }\left(\sigma_{\mathrm{u}}{ }^{2}+\sigma_{\mathrm{e}}{ }^{2}\right)$ or $\left.1.21 \sigma_{\mathrm{e}}\right)$. The frequency of the major locus allele that increases $\mathrm{SaO}$ was estimated to be $\mathrm{p}_{\mathrm{B}}=0.53$. This locus alone would explain $48 \%$ of the total variance and $87 \%$ of the total genetic variance in $\mathrm{SaO}$. The additive genetic variance accounted for by the major locus would be $79 \%$ of the total additive genetic variance.

\section{Deleted: less}

Deleted: [TABLE 1],

Deleted: . Table 4 shows estimates of $\sigma_{u}^{2}, \sigma_{\mathrm{e}}^{2}$ and $\sigma_{\mathrm{p}}^{2}$ obtained from the REML analyses for blood oxygen saturation

Deleted: , [TABLE 4]

Deleted: For all runs and parameters, chains seemed to have converged to their equilibrium distributions after a 5000 iteration burn-in period and sample autocorrelation was generally low (absolute values smaller than 0.1) for lags over 100 for all parameters (results not shown). Marginal posterior distribution of all parameters were symmetric and approximated normal distributions. Table

5 shows the marginal posterior means,

posterior standard deviations, Monte Carlo standard deviation of marginal posterior means and the effective number of samples per chain for all sampled parameters. The difference between marginal posterior means from the six chains ran for data set 1 was not always strictly within the Monte Carlo sampling error estimated as proposed by Geyer (1992). Nonetheless, all chains seemed to have converged to the equilibrium distribution (using different starting values) and marginal posterior means were very close. The effective number of samples was variable within chains

between parameters and within parameters between chains, with values ranging from nine to more than 600 independent samples. Generally $\sigma_{u}{ }^{2}$ and $\sigma_{e}{ }^{2}$ showed smaller effective numbers of samples, which reflects poorer mixing for these parameters.II

[TABLE 5]"I

Samples were pooled across chains and the means of the pooled distributions and their standard deviations were used as point estimates of the sampled parameters and their standard errors. Since the total number of independent samples for any parameter was greater than 100 , the mean and the standard deviation of the pooled posterior distribution were assumed to be good estimates of the parameter and its standard error.

Deleted: 6

Deleted: shows point estimates of the parameters sampled and those derived and the standard deviation of their pooled posterior distributions. All distributions presented zero densities for parameter values equal to zero. Following Janss et al. (1995) we inferred that a locus with large effect on $\mathrm{SaO}$ was segregatin ... [2]

Deleted: Although the estimated d was slightly larger than a, estimated major locus effects were similar in size (the dominance deviance was estimated to be

$1.12( \pm 0.06)$ and was indeed just different from one. $\mathrm{W}$

Deleted: with $\mathrm{a}=\mathrm{d}$

Deleted: .

Deleted: It follows 
[TABLE 4$]$

Figures 2 and 3 show respectively the distributions of a and $d$ and of $p_{\mathrm{B}}$ for data sets 1 and 2. The estimated locus effects obtained from the analysis of data set 2 were roughly the same, although slightly smaller, than the estimates obtained from the analysis of data set 1: the estimate of a from data set 2 was proportionately 0.89 the estimate from data set 1 and the estimated d was 0.82 the estimate from data set 1 . Despite this, the standardized locus additive effect increased from 0.80 to $0.87 \sigma_{\mathrm{p}}$. The estimated $\mathrm{p}_{\mathrm{B}}$ was 0.65 that is 0.12 higher than the estimate obtained from data set 1 .This major locus would explain $33 \%$ of the total variance observed for $\mathrm{SaO}$ in data set 2 and $82 \%$ of the total genetic variance. The additive genetic variance accounted for by the major locus was estimated to be $70 \%$ of the total additive genetic variance.

\section{[FIGURE 1], [FIGURE 2], [FIGURE 3]}

Sampled Genotype Probabilities and Allele Frequencies. The correlation between chains of estimated probabilities for each genotype for individual birds was higher than 0.96 , and the mean standard error (averaging over all birds with data and ancestors) of each genotype probability was smaller than 0.01 .

Sire genotype probabilities obtained from data set 2 show that approximately $1.8 \%$ of the sires were assigned a bb genotype, $32.9 \%$ a $\mathrm{Bb}$ genotype and $11.1 \%$ a BB genotype with a probability higher than 0.8 . If the inferred mode of action of the putative gene is dominant, information from relatives is necessary to discriminate heterozygotes from the dominant homozygotes. In our case, more than $40 \%$ of sires were identified as being either $\mathrm{BB}$ or $\mathrm{Bb}$ with high probability $(>0.8)$ but around a further $15 \%$ of sires had similar (and close to 0.5 ) probabilities of being $\mathrm{BB}$ or $\mathrm{Bb}$, although they had very low probabilities of being bb.

Figure 4 shows how major allele frequencies vary over time for data set 2. Estimates of allele frequencies were obtained from sires alone and from all birds with records. For sires, each point in the graph was obtained from 29 birds whereas in the case of selection candidates each point was obtained from 1000 birds. For selection candidates, regression of allele frequencies over time has a negative slope for $\mathrm{p}_{\mathrm{b}}$ and a positive one for $\mathrm{p}_{\mathrm{B}}$, showing how within the period
Deleted: Table 6 also shows the means and standard deviations of the pooled distributions for the sampled and derived parameters for data set 2 . The visual inspection of the six chains did not show convergence problems. Figure 1 shows the pooled posterior distributions of $\sigma_{\mathrm{u}}{ }^{2}$, $\sigma_{\mathrm{m}}{ }^{2}$ and $\sigma_{\mathrm{e}}{ }^{2}$ for data set 2. Pooled posterior distributions for all parameters presented zero densities for parameter values equal to zero. Since the density at zero for $\sigma_{\mathrm{m}}{ }^{2}$ was zero, presence of a locus with large effect on $\mathrm{SaO}$ segregating in the population was inferred. The estimated dominance deviance was not different from one, so the putative locus was assumed to act in a dominant fashion.

Deleted: pooled posterior
Deleted: Analyses were repeated for data set 2 , using raw phenotypes (records not adjusted for fixed effects) and sampling fixed effects (age of dam and hatch). These analyses yielded estimates of the parameters presented in table 6 that were similar to the ones obtained from adjusted phenotypes (results not shown), showing that, in this case, preadjustement of phenotypes did not have a significant effect on parameter estimates.II 
218

219

220

221

222 corresponding to data set 2 the frequency of the major allele that increases $\mathrm{SaO}$ increased over time.

[FIGURE 4]

Estimation of the Putative Locus Effect on Weight and Fleshing Score. Table, 5 shows the estimates of the putative locus additive and dominance effect on $\mathrm{SaO}$, Weight and Flesh obtained from the regression of trait values on genotype probabilities at the major locus using data set 2 . The estimated additive effect was not different from zero for Weight and Flesh, but the estimated dominance effect was large for both. This suggests that birds heterozygous at this putative locus would have substantially higher body weight and fleshing score at five weeks than either of the homozygotes. The estimated effects for $\mathrm{SaO}$ were significantly larger than the estimates obtained from the segregation analysis.

[TABLE 5]

\section{DISCUSSION}

Overall, the segregation analyses of $\mathrm{SaO}$ data indicate that a locus with large effect is involved in the genetic control of $\mathrm{SaO}$ in this line. Results obtained from the two sets of data provide a consistent picture: a dominant major locus with an additive effect of around $0.90 \sigma_{\mathrm{p}}$ that is responsible for a predicted difference in $\mathrm{SaO}$ between the two homozygotes of more than $10 \%$ is segregating in this line. The frequency of the allele that increases $\mathrm{SaO}$ increased with selection on $\mathrm{SaO}$ from $\mathrm{p}_{\mathrm{B}}=0.53$ to around 0.65 . It is difficult to assess if the observed difference in estimated $\mathrm{p}_{\mathrm{B}}$ from data sets 1 and 2 really reflects a change in allele frequencies over time or is a consequence of phenotypes recorded at different ages (six and five weeks respectively). Nonetheless, Figure 4 shows that, within a time period (data set 2), the estimated frequency of the allele that increases $\mathrm{SaO}$ increases slightly over time, which is consistent with the between data set trend.

For data set 1 , the predicted proportion of heterozygous individuals would be around $50 \%$. Because the gene is dominant, around $25 \%$ of the population would show low $\mathrm{SaO}$ values. Despite this, this locus alone would explain $48 \%$ of the total variance and around $87 \%$ of the genetic variance in the "base population". For data set 2, the predicted proportion of 
heterozygous individuals would be around $45 \%$ and only around $12 \%$ of the population would show low $\mathrm{SaO}$ values. The proportion of the total variance observed in the data set 2 "base population" explained by this putative locus has decreased to $33 \%$ and that of the genetic variance to $80 \%$. From data set 1 to data set 2, the estimate of the major locus variance has more than halved. Changes in the major locus allele frequency alone account for $71 \%$ of this difference compared to $46 \%$ accounted for by changes in estimated effects alone. The polygenic variance estimated from data set 2 was roughly two thirds of the estimate obtained from data set 1. This, together with an increase in the frequency of the allele that increases $\mathrm{SaO}$, is consistent with the fact that increasing $\mathrm{SaO}$ has been one of the breeding goals in the population studied. As a result of decreases in major gene and polygenic variances, the total and the major locus heritabilities have decreased, since the residual variance has remained approximately constant. Note that the frequencies of birds with low $\mathrm{SaO}$ values in the two data sets do not necessarily provide a direct prediction of the expected frequency of ascites as the correlation between ascites and $\mathrm{SaO}$ in this population is unknown. In fact we might predict that a low $\mathrm{SaO}$ value predisposes a bird to ascites, but the actual development of ascites is also dependent on other environmental factors. For example, Julian and Mirsalimi (1992) showed that there was a significant mean difference in $\mathrm{SaO}$ between ascitic and non-ascitic birds from a heavy meattype chicken, but not all birds with low $\mathrm{SaO}$ developed ascites during their trial.

\section{susceptibility tend to suggest that this trait is influenced by a single biallelic major locus that would act in a recessive fashion (see for example, Druyan et al. (2001), Druyan et al. (2002), Wideman and French (1999) and Wideman and French (2000)) and this would support our findings.}

The mean skewness coefficient of our data sets (after adjustment for fixed effects) was around -0.77 . In an outbred situation, where one expects only a proportion of families to be segregating at a putative major locus, the trait distribution within full and/or half sib families would depend on the sire and dam major genotypes, and families that do not segregate at the major locus would only show "background skewness" (i.e., skewness not caused by the major \begin{tabular}{l} 
Deleted: selection being carried out to \\
\hline Deleted: e
\end{tabular} 
locus segregation). Figure 5 shows the distribution of adjusted $\mathrm{SaO}$ phenotypes within two sire families with over 100 offspring each. Sire 1 was assigned a $\mathrm{Bb}$ genotype with a probability greater than 0.99 in the segregation analysis whereas sire 2 was assigned a BB genotype with a probability greater than 0.98 and a bb genotype with a probability smaller than 0.02 . It can be seen that dispersion within sire family 1 is larger than dispersion within sire family 2 , which is consistent with the predicted genotype status of the two sires.

\section{[FIGURE 5]}

\section{We observed that, for the analyses carried out, the total additive variance estimated using a mixed inheritance model was greater than the additive variance estimated using a polygenic model. We carried out a simulation study, presented in the annex, that supports the hypothesis that changes in allele frequencies caused by selection are the source of the observed discrepancies.}

By regressing Weight and Flesh phenotypes on functions of major locus genotype probabilities we obtained estimates of the effects of the putative locus on these traits. The locus that has an effect on $\mathrm{SaO}$ seems to act in an overdominant fashion for weight and fleshing score. This would be consistent with the estimate of zero for the genetic correlation between these traits and oxygen saturation from the analysis done assuming a purely polygenic model with additive genetic effects and would also explain the intermediate frequency of the high $\mathrm{SaO}$ allele estimated from data set 1 , which increases after selection to increase oxygen saturation. In an experiment involving the hypobaric exposure of birds, Pavlidis et al. (2003) observed significant heterosis for body weight at 14,18 and 42 days in the reciprocal crosses of an ascites-resistant and an ascites-susceptible line, but observed no differences in body weight between the ascites-resistant and ascites-susceptible lines. These observations fit well with our results. Estimates of the putative gene effects for $\mathrm{SaO}$ obtained from this analysis were approximately two-fold the ones obtained from the segregation analysis. Genotype probabilities were estimated from segregation analysis and only birds with phenotypes from the tails of the $\mathrm{SaO}$ trait distribution (and/or strong family information) are likely to have extreme (i.e., close to 0 or 1) estimates of genotype probabilities. This would cause these individuals to have a high
Deleted: MacLean et al. (1976) suggested applying a transformation to the phenotypic data to remove skewnes prior to analysis, but showed that this prior to analysis, but showed hat this detect major genes when present, as well as posing problems for the interpretation of the results (Demenais et al., 1986). Using data set 2, we applied a transformation to $\mathrm{SaO}$ data, in order to obtain a trait distribution closer to a Normal. The transformation applied was $\mathrm{Ln}(100-\mathrm{SaO})$, and the transformed trait distribution had a skewness coefficient of -0.29 and a kurtosis coefficient of -0.17 . The heritability of $\mathrm{Ln}(100-\mathrm{SaO})$ was

0.14 , which is almost identical to that obtained for untransformed data. The outcome of the analysis of transformed data was that a dominant locus with large effect on $\operatorname{Ln}(100-\mathrm{SaO})\left(\mathrm{a}=\mathrm{d}=0.58 \sigma_{\mathrm{p}}\right)$ was segregating in this line, but neither the frequency nor the mode of action of this putative locus were in agreement with the results obtained from untransformed data. Indeed, an allele that increases $\mathrm{Ln}(100-\mathrm{SaO})$ would decrease $\mathrm{SaO}$, so the estimated $\mathrm{p}_{\mathrm{B}}=0.69$ from this analysis needs to be compared to $(1-$ $0.65)=0.35$. In the same way, if the locus that increases $\mathrm{Ln}(100-\mathrm{SaO})$ were dominant, the proportion of birds showing low $\mathrm{SaO}$ values would be around $81 \%$ compared with the predicted $12 \%$ from the untransformed data analysis. Moreover, the correlation between the probability of a bird being heterozygote estimated from transformed and untransformed data was $-0.17(\mathrm{P}<$ $0.001)$ for birds with $\mathrm{SaO}$ data and -0.11 $(\mathrm{P}=0.03)$ for sires with $\mathrm{SaO}$ data. The

fact that the estimates of $\mathrm{p}_{\mathrm{Bb}}$ are not similar from transformed and untransformed data suggests that these analyses are describing different phenomena. Selection experiments carried out in other broiler populations to study ascites susceptibility tend to suggest that this trait is influenced by a single biallelic major locus that would act in a recessive fashion (see for example, Druyan et al. (2001), Druyan et al. (2002), Wideman and French (1999) and

Wideman and French (2000)). This would support the mode of action suggested for $\mathrm{SaO}$ by the analysis of untransformed data.II

We observed that, for the analyses carried out, the total additive variance estimated using a mixed inheritance model was greater than the additive variance estimated using a polygenic model. In order to assess whether this would be expected in the presence of a segregating major gene in a population under selection a simulation study was performed. 125 five-generation pedigrees (base population and four generations of random or phenotypic selection) were simulated with a structure chosen to resemble the (real) pedigree analyzed. In each generation, 40 males were mated to eight (different) females that produced three male and three female offspring each (i.e., population size was maintained constant). In the case of phenotypi ... [3] 
302 influence in the regression and hence could lead to an overestimation of the locus effect for

$303 \mathrm{SaO}$. The extent to which this would affect estimates of effects for Weight and Flesh would be a

304 function of the true genetic correlation amongst these traits and $\mathrm{SaO}$.

\section{Conclusions and further research}

Our study indicates that a QTL or gene with large effect on $\mathrm{SaO}$ is segregating in the population studied. It must be borne in mind that, although segregation analysis is the most powerful marker-free method for major gene or QTL detection, it is sensitive to deviations from normality, and the distribution of the data analyzed was skewed. Nevertheless, the majority of the different analyses performed here are consistent with the presence of a major gene. Only the result from the analysis of transformed data (presented in the annex) provides a cautionary note, but previous studies suggest this may be expected even in the presence of a genuine major gene. Accepting the presence of a major gene, the mode of action of the putative locus on $\mathrm{SaO}$ and on weight and fleshing score, the fixation of the favourable allele (i.e., the one that increases $\mathrm{SaO}$ ) by means of traditional selection would be a difficult task. Under selection only for growth and carcass characteristics, the low $\mathrm{SaO}$ allele would be maintained in the population by the advantage of the heterozygous bird. The combined effects of selection to increase both $\mathrm{SaO}$ and weight and fleshing score will reduce the fitness of the low $\mathrm{SaO}$ homozygote, but will still result in the heterozygote being the favoured genotype and hence the low $\mathrm{SaO}$ allele will be retained in the population. Nonetheless, elimination of carriers of the allele that decreases $\mathrm{SaO}$ is of interest since it would lead to greatly improved broiler health, would reduce the broiler industry ascites-related economic losses and remove the need for continual $\mathrm{SaO}$ testing. However, given the estimated effects of the locus, this would be most effectively achieved using genetic markers to identify and select against the low $\mathrm{SaO}$ allele. A QTL mapping study in a suitable population is a necessary further step that would confirm or refute our findings and identify potential markers to manipulate the low $\mathrm{SaO}$ allele. 


\section{ACKNOWEDGEMENTS}

We acknowledge support from the Biotechnology and Biological Sciences Research Council. PN is also grateful to Aviagen Ltd. for funding and to Ricardo Pong-Wong for providing data analysis software.

\section{REFERENCES}

DEMENAIS, F., LATHROP, M. \& LALOUEL, J.M. (1986) Robustness and power of the unified model in the analysis of quantitative measurements. American Journal of Human Genetics, 38: 228-234.

DRUYAN, S., BEN-DAVID, A., BELlAICHE, M., ROSNER, A., SHLOSBERG, A. \& CAHANER, A. (2001) Genetic differences in the susceptibility of broilers to ascites. Pages 8586 in Proceedings of the $2^{\text {nd }}$ European Poultry Genetics Symposium, Gödöllö, Hungary.

DRUYAN, S., BEN-DAVID A., BELlAICHE, M., SHLOSBERG, A., YAHAV, S. \& CAHANER A. (2002) Indications for a major gene for broiler susceptibility to ascites. Page 300 in Proceedings of the $11^{\text {th }}$ European Poultry Conference, Bremen, Germany.

ELSTON, R.C. \& STEWART, J. (1971) General model for genetic analysis of pedigree data. Human Heredity, 21: 523-542.

FALCONER, D. S. \& MACKAY, T. F. C. (1996) Introduction to quantitative genetics. 4th ed. (Harlow (UK), Longman).

FISHER, R. A. (1918) The correlation between relatives under the supposition of Mendelian inheritance. Transactions of the Royal Society of Edinburgh, 52: 399-433.

GENSTAT 5 COMMITTEE (1993) GenstatTM 5 Release 3 reference manual. (Oxford (UK), Clarendon Press).

GEYER, C. J. (1992) Practical Markov chain Monte Carlo. Statistical Science, 7: 473-511. 
GILMOUR, A. R., CULLIS, B. R., WELHAM, S. J. \& THOMPSON, R. (2000) ASREML Reference Manual. 2nd ed. Release 1.0 NSW Agriculture Biometrical Bulletin 3. (Orange (Australia)) ftp://ftp.res.bbsrc.ac.uk/pub/aar/

GUO, S.W. \& THOMPSON, E.A. (1991) Monte-Carlo estimation of variance component models for large complex pedigrees. Ima Journal of Mathematics Applied in Medicine and Biology, 8: 171-189.

GUO, S.W. \& THOMPSON, E.A. (1994) Monte-Carlo estimation of mixed models for large complex pedigrees. Biometrics, 50: 417-432.

HANSET, R. \& MICHAUX, C. (1985) On the genetic determinism of muscular hypertrophy in the Belgian white and blue cattle breed .1. Experimental-data. Genetics Selection Evolution, 17: 359-368.

HANSET, R. \& MICHAUX, C. (1985) On the genetic determinism of muscular hypertrophy in the Belgian white and blue cattle breed .2. Population-data. Genetics Selection Evolution, 17: 369-385.

JANSS, L.L.G., THOMPSON, R. \& VANARENDONK, J.A.M. (1995) Application of Gibbs sampling for inference in a mixed major gene-polygenic inheritance model in animal populations. Theoretical and Applied Genetics, 91: 1137-1147.

JANSS, L.L.G., VANARENDONK, J.A.M. \& BRASCAMP, E.W. (1997) Bayesian statistical analyses for presence of single genes affecting meat quality traits a crossed pig population. Genetics, 145:395-408.

JULIAN, R.J. \& MIRSALIMI, S.M. (1992) Blood-oxygen concentration of fast-growing and slow-growing broiler-chickens, and chickens with ascites from right ventricular failure. Avian Diseases, 36: 730-732. 
373

374

375

376

377

378

379

380

381

382

383

384

385

386

387

388

389

390

391

392

393

394

395

KNOTT, S.A., HALEY, C.S. \& THOMPSON, R. (1992) Methods of segregation analysis for animal breeding data - a comparison of power. Heredity, 68: 299-311.

MACLEAN, C.J., MORTON, N.E. \& LEW, R. (1975) Analysis of family resemblance .4. Operational characteristics of segregation analysis. American Journal of Human Genetics, 27: 365-384.

MACLEAN, C.J., MORTON, N.E., ELSTON, R.C. \& YEE, S. (1976) Skewness in commingled distributions. Biometrics, 32: 695-699.

MILAN, D., JEON, J.T., LOOFT, C., AMARGER, V., ROBIC, A., THELANDER, M., ROGEL-GAILlARD, C., PAUL, S., IANNUCCELli, N., RASK, L., RONNE, H., LUNDSTROM, K., REINSCH, N., GELLIN, J., KALM, E., LE ROY, P., CHARDON, P. \& ANDERSSON, L. (2000) A mutation in PRKAG3 associated with excess glycogen content in pig skeletal muscle. Science, 288: 1248-1251.

MINITAB (1998) MINITAB Reference Manual Release 12. (Coventry (UK), MINITAB).

MORTON, N.E. \& MACLEAN, C.J. (1974) Analysis of family resemblance .3. Complex segregation of quantitative traits. American Journal of Human Genetics, 26: 489-503.

NAVARRO, P., VISSCHER, P. M., CHATZIPLIS, D., KOERHUIS, A. N. M. \& HALEY, C. S. (2006) Genetic parameters for blood oxygen saturation, body weight and breast conformation in four meat-type chicken lines. British Poultry Science (Submitted)

PAVLIDIS, H. O., BALOG, J. M., STAMPS, L., HUFF, G.R., HUFF, W. E., RATH, N. C., CISAR, C. R., TELLEZ, G. \& ANTHONY, N. B. (2003) Effect of hypobaric hypoxia on ascites resistant and susceptible lines and their reciprocal F1 crosses. 1. Production parameters and ascites mortality. In Proceedings of the Annual Meeting of the Poultry Science Association, Madison, WI. http://www.poultryscience.org/psa03/abstracts/abs11.pdf. Accessed Sept. 2003. 
PIPER, L. R. \& BINDON, B. M. (1982) Genetic segregation for fecundity in Boroola Merino sheep. Pages 395-400 in Volume 1 of the Proceedings of the World conference on Sheep and Beef Cattle Breeding. (Palmerston North (New Zealand), Dunmore Press).

SORENSEN, D.A., ANDERSEN, S., GIANOLA, D. \& KORSGAARD, I. (1995) Bayesianinference in threshold models using Gibbs sampling. Genetics Selection Evolution, 27: 229-249.

TURELLI, M. \& BARTON, N.H. (1994) Genetic and statistical-analyses of strong selection on polygenic traits - what, me normal. Genetics, 138: 913-941.

WALLING, G.A., BISHOP, S.C., PONG-WONG, R., GITTUS, G., RUSSEL, A.J.F. \& RHIND, S.M. (2002) Detection of a major gene for litter size in Thoka Cheviot sheep using Bayesian segregation analyses. Animal Science. 75:339-348.

WIDEMAN, R.F., WING, T., KIRBY, Y.K., FORMAN, M.F., MARSON, N., TACKETT, C.D. \& RUIZ-FERIA, C.A. (1998) Evaluation of minimally invasive indices for predicting ascites susceptibility in three successive hatches of broilers exposed to cool temperatures. Poultry Science, 77: 1565-1573.

WIDEMAN, R.F. \& FRENCH, H. (1999) Broiler breeder survivors of chronic unilateral pulmonary artery occlusion produce progeny resistant to pulmonary hypertension syndrome (ascites) induced by cool temperatures. Poultry Science, 78: 404-411.

WIDEMAN, R.F. \& FRENCH, H. (2000) Ascites resistance of progeny from broiler breeders selected for two generations using chronic unilateral pulmonary artery occlusion. Poultry Science, 79: 396-401. 
1

2
Table 1. Structure of data for oxygen saturation (SaO), body weight (Weight) and

fleshing score (Flesh) for data sets 1 and 2.

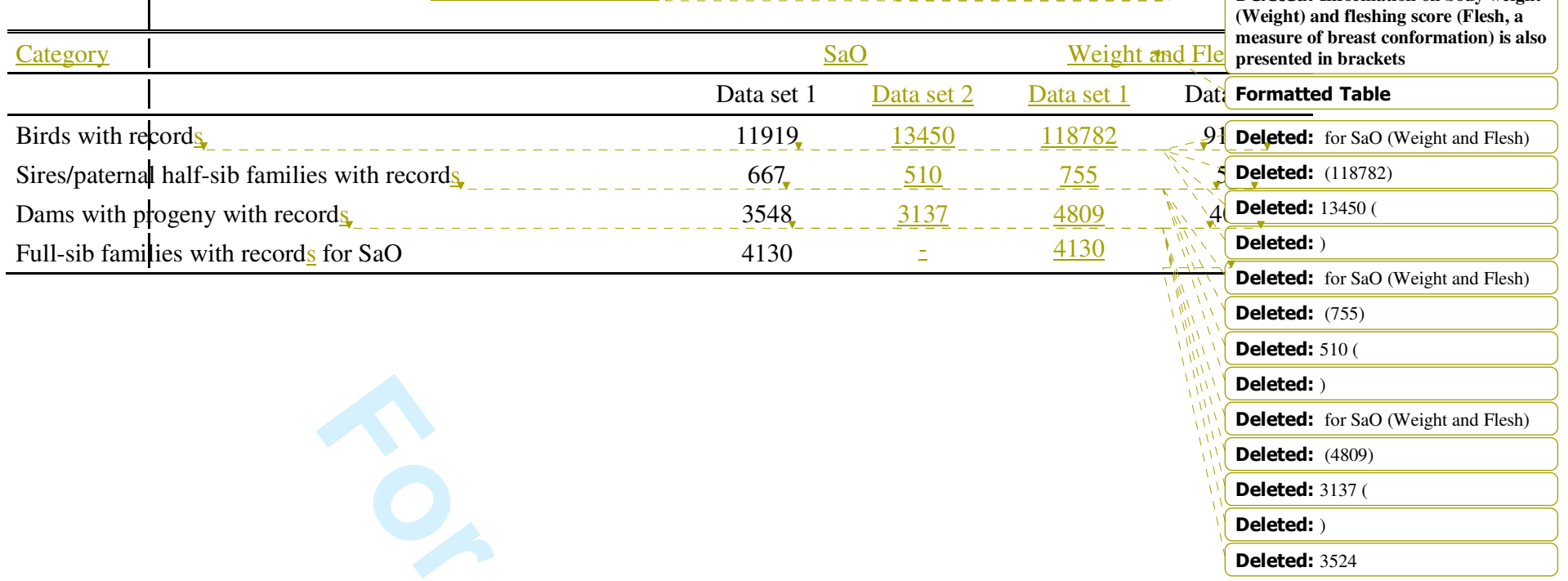


Table 2. Means and standard deviations (in brackets) for blood oxygen saturation

419 (SaO, in \% units), body weight (Weight, in kg) and fleshing score (Flesh, a measure of breast conformation, in arbitrary units, measured in a scale of 1 to 5) for raw phenotypes

(RAW) and for SaO phenotypes adjusted for fixed effects (ADJ) for data sets 1 and 2.

Skewness (Sk) and kurtosis ( $\mathrm{Ku}$ ) coefficients of the distributions of raw $\mathrm{SaO}$ phenotypes and analyzed data are also presented

\begin{tabular}{llccccc}
\hline Data set & & $\mathrm{SaO}(\%)$ & Weight $(\mathrm{kg})$ & Flesh (units) & Sk & $\mathrm{Ku}$ \\
\hline 1 & RAW & $80.02(9.15)$ & $2.72(0.34)$ & $3.17(0.92)$ & -0.78 & 0.46 \\
& ADJ & $0.64(8.08)$ & - & - & -0.75 & 1.06 \\
2 & RAW & $81.81(7.98)$ & $2.16(0.28)$ & $3.10(0.90)$ & -0.85 & 0.88 \\
& ADJ & $-0.42(7.23)$ & - & - & -0.74 & 0.93 \\
\hline
\end{tabular}


Table 3. Heritabilities (on diagonal) and genetic correlations (below diagonal) and their standard errors (in brackets), obtained for body weight (Weight), fleshing score

(Flesh, a measure of breast conformation) and blood oxygen saturation (SaO) estimated by

REML from data set 1 (traits measured at six weeks) and data set 2 (traits measured at

five weeks) using full pedigrees

\begin{tabular}{llccc}
\hline Data set & & $\mathrm{SaO}$ & Weight & Flesh \\
\hline 1 & $\mathrm{SaO}$ & $0.21(0.02)$ & & \\
& Weight & $-0.02(0.06)$ & $0.26(0.01)$ & \\
& Flesh & $-0.10(0.05)$ & $0.53(0.03)$ & $0.22(0.01)$ \\
& $\mathrm{SaO}$ & $0.15(0.02)$ & & \\
& Weight & $-0.10(0.06)$ & $0.32(0.01)$ & \\
& Flesh & $-0.10(0.06)$ & $0.62(0.02)$ & $0.19(0.01)$ \\
\hline
\end{tabular}


Table 4. Point estimates and standard deviations (in brackets) of the major locus additive (a) and dominance (d) effect, $\mathrm{B}$ allele frequency $\left(\mathbf{p}_{\mathrm{B}}\right)$, population mean (Mean) and residual $\left(\sigma_{\mathrm{e}}{ }^{2}\right)$ and polygenic $\left(\sigma_{\mathrm{u}}{ }^{2}\right)$ variances obtained from the segregation analysis of SaO for data sets 1 and 2. Estimates are also presented for the major locus variance $\left(\sigma_{\mathrm{m}}{ }^{2}=2 \mathrm{p}_{\mathrm{B}}\left(1-\mathrm{p}_{\mathrm{B}}\right)\left[\mathrm{a}+\mathrm{d}\left(\left(1-\mathrm{p}_{\mathrm{B}}\right)-\mathrm{p}_{\mathrm{B}}\right)\right]^{2}+\left[2 \mathrm{p}_{\mathrm{B}}\left(1-\mathrm{p}_{\mathrm{B}}\right) \mathrm{d}\right]^{2}\right)$, total phenotypic variance $\left(\sigma_{\mathrm{p}}{ }^{2}=\sigma_{\mathrm{m}}{ }^{2}+\sigma_{\mathrm{u}}{ }^{2}+\sigma_{\mathrm{e}}{ }^{2}\right)$, variance ratios $\left(h_{\mathrm{T}}=\left(\sigma_{\mathrm{m}}{ }^{2}+\sigma_{\mathrm{u}}{ }^{2}\right) / \sigma_{\mathrm{p}}{ }^{2}, \mathrm{~h}_{\mathrm{m}}=\sigma_{\mathrm{m}}{ }^{2} / \sigma_{\mathrm{p}}{ }^{2}, \mathrm{~h}_{\mathrm{am}}=\left(2 \mathrm{p}_{\mathrm{B}}\left(1-\mathrm{p}_{\mathrm{B}}\right)\left[\mathrm{a}+\mathrm{d}\left(\left(1-\mathrm{p}_{\mathrm{B}}\right)-\mathrm{p}_{\mathrm{B}}\right)\right]^{2}\right) / \sigma_{\mathrm{p}}{ }^{2}\right.$ and $\left.\mathrm{h}=\sigma_{\mathrm{u}}{ }^{2} /\left(\sigma_{\mathrm{u}}{ }^{2}+\sigma_{\mathrm{e}}{ }^{2}\right)\right)$ and dominance deviance $(\mathrm{d} / \mathrm{a})$

\begin{tabular}{lcccccccccccccccc}
\hline \hline Data set & $\mathrm{a}$ & $\mathrm{d}$ & $\mathrm{p}_{\mathrm{B}}$ & Mean & $\sigma_{\mathrm{e}}{ }^{2}$ & $\sigma_{\mathrm{u}}{ }^{2}$ & $\sigma_{\mathrm{m}}{ }^{2}$ & $\sigma_{\mathrm{p}}{ }^{2}$ & $\mathrm{~h}_{\mathrm{T}}$ & $\mathrm{h}_{\mathrm{m}}$ & $\mathrm{h}_{\mathrm{am}}$ & $\mathrm{h}$ & $\mathrm{d} / \mathrm{a}$ \\
\hline \multirow{2}{*}{1} & 7.22 & 8.05 & 0.53 & -5.60 & 35.58 & 6.06 & 39.19 & 80.83 & 0.56 & 0.48 & 0.36 & 0.14 & 1.12 \\
& $(0.20)$ & $(0.32)$ & $(0.03)$ & $(0.33)$ & $(1.14)$ & $(1.00)$ & $(3.10)$ & $(3.07)$ & $(0.02)$ & $(0.02)$ & $(0.03)$ & $(0.02)$ & $(0.06)$ \\
& & & & & & & & & & & & \\
2 & 6.46 & 6.60 & 0.65 & -4.84 & 32.67 & 3.93 & 18.25 & 54.85 & 0.40 & 0.33 & 0.17 & 0.11 & 1.02 \\
& $(0.21)$ & $(0.32)$ & $(0.02)$ & $(0.26)$ & $(0.85)$ & $(0.62)$ & $(1.82)$ & $(1.84)$ & $(0.02)$ & $(0.02)$ & $(0.02)$ & $(0.02)$ & $(0.06)$ \\
\hline
\end{tabular}


1

2

3437 4

7 8 9

445

Table 5. Estimates and standard errors (in brackets) of the putative locus additive (a)

439 and dominance (d) effect for blood oxygen saturation (SaO), body weight (Weight) and fleshing

440 score (Flesh, a measure of breast conformation) obtained from the regression of trait values on

441 genotype probabilities at the major locus. Data recorded at five weeks of age (data set 2) were

$442 \quad$ used to obtain these estimates

\begin{tabular}{lcc}
\hline \hline Trait & $\mathrm{a}$ & $\mathrm{d}$ \\
\hline $\mathrm{SaO}(\%)$ & $11.96(0.14)^{* *}$ & $16.61(0.27)^{* *}$ \\
Weight (kg) & $-0.71 \times 10^{-2}\left(0.55 \times 10^{-2}\right)$ & $5.84 \times 10^{-2}\left(0.88 \times 10^{-2}\right)^{* *}$ \\
Flesh (units) & $-0.03(0.02)$ & $0.24(0.04)^{*}$
\end{tabular}

$443 \quad$ * Significantly different from $0(\mathrm{P} \leq 0.05)$

$444 * *$ Significantly different from $0(\mathrm{P} \leq 0.01)$. 
447

448
Figure 1. Pooled posterior distributions of the polygenic $\left(\sigma_{\mathrm{u}}{ }^{2}\right)$, major locus $\left(\sigma_{\mathrm{m}}{ }^{2}\right)$ and residual $\left(\sigma_{\mathrm{e}}{ }^{2}\right)$ variances obtained from data set 2 
(b)

$$
\text { Frequency (\%) }
$$

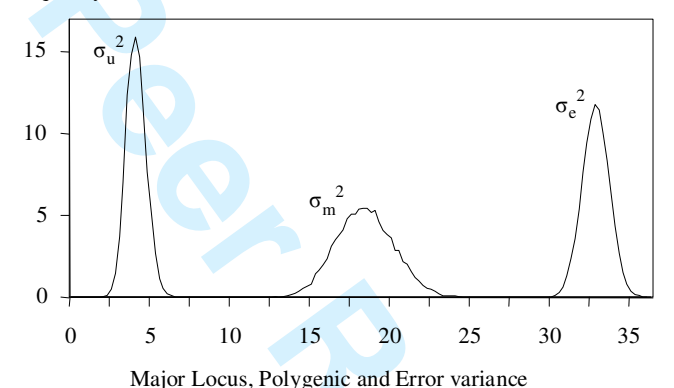

Locus, Polygenic and Error variance

SEGREGATION ANALYSIS BLOOD OXYGEN SATURATION, FIGURE 1

Frequency (\%)
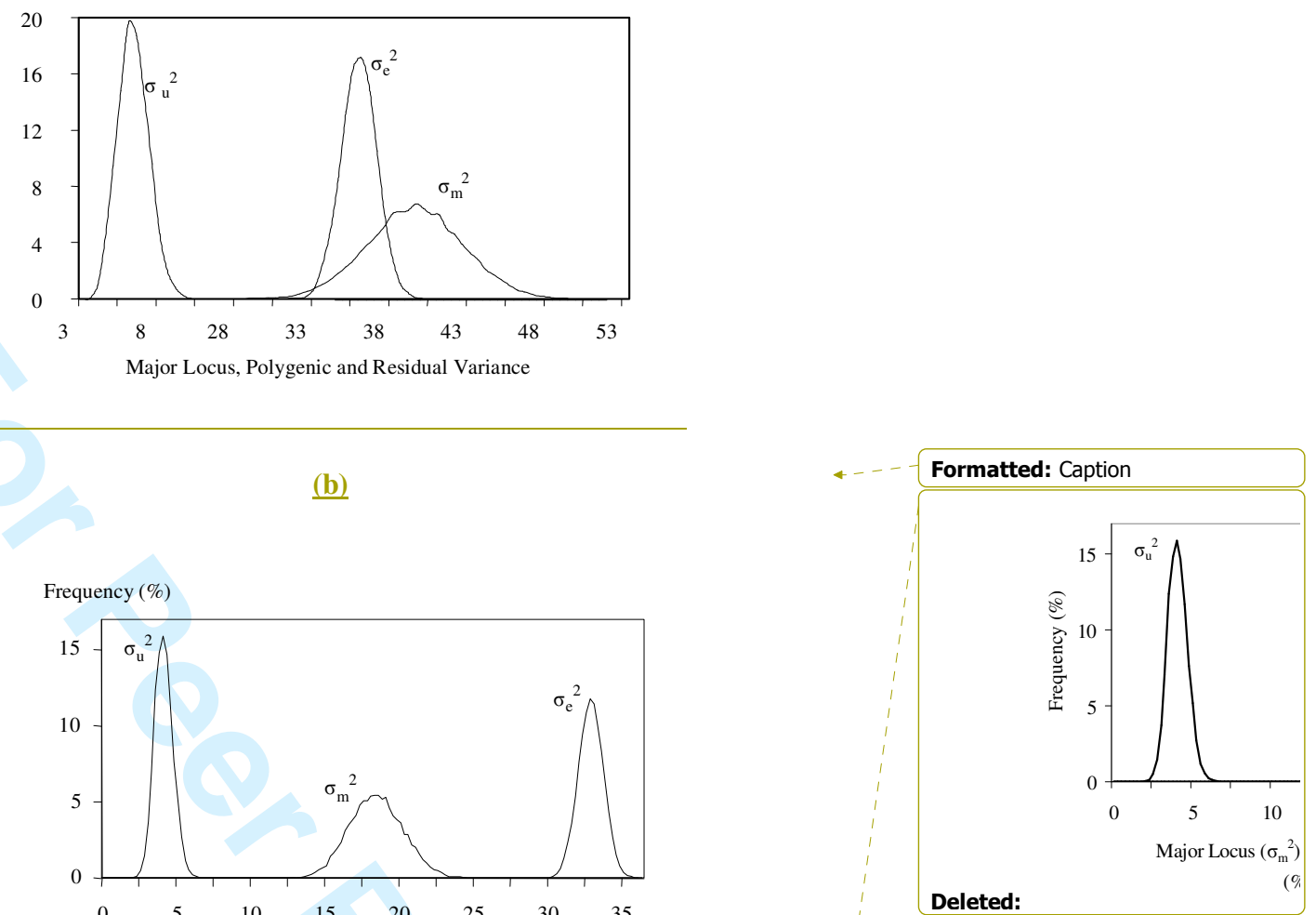
459

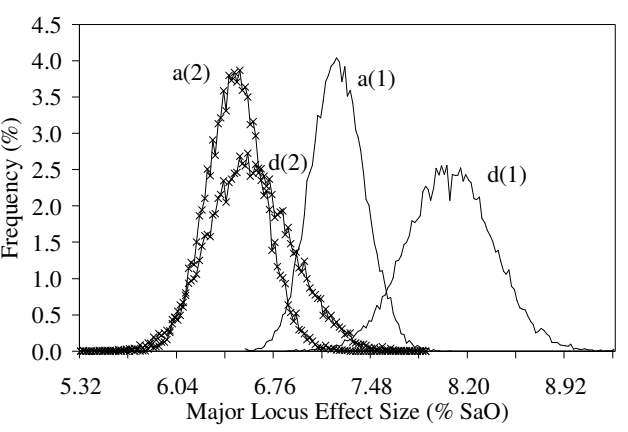

460

461

SEGREGATION ANALYSIS BLOOD OXYGEN SATURATION, FIGURE 2

463 
Figure 3. Pooled posterior distributions of the major allele $B$ frequency 


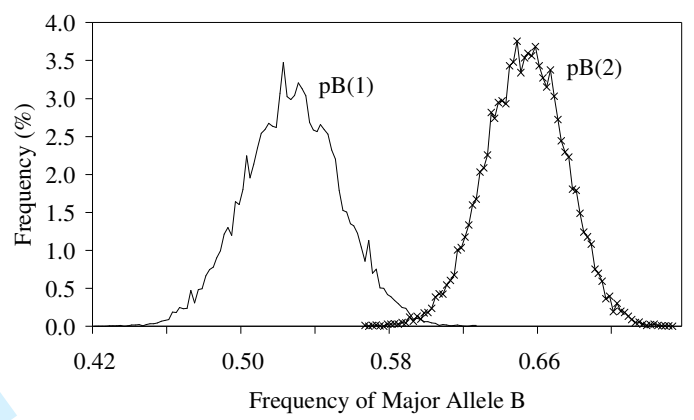

468 469 
Figure 4. Major allele frequencies plotted over time. Estimates of allele frequencies were obtained from sires alone and from all birds with records 
474

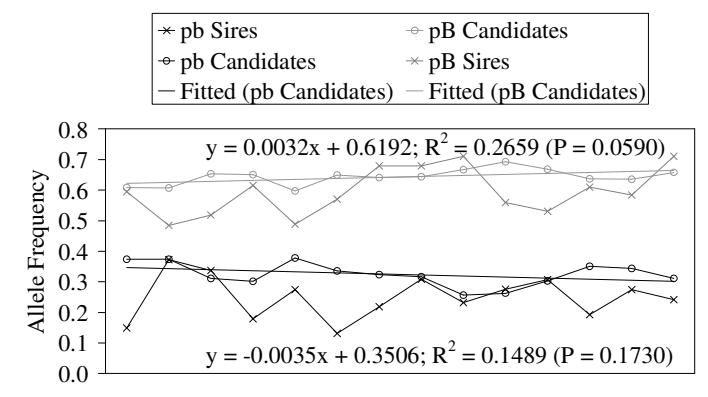

476 
$479 \quad$ Figure 5. Distribution of adjusted $\mathrm{SaO}$ phenotypes within two sire families with

480 over 100 offspring each. The genotypes of sire 1 and sire 2 were estimated to be

481

482

heterozygous $\mathrm{Bb}$ and homozygous $\mathrm{BB}$, with probabilities higher than 0.99 and 0.98

respectively. 


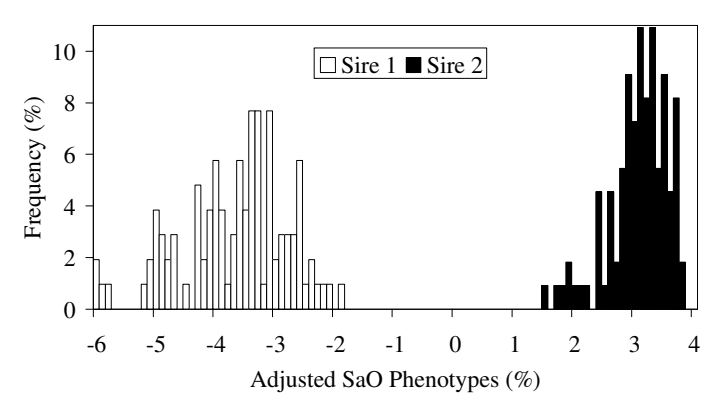

485 
Segregation Analysis. The mixed model equation that describes the model fitted to

$\mathbf{y}=\mathbf{X b}+\mathbf{Z u}+\mathbf{Z W m}+\mathbf{e}$

$\underline{\text { where } \mathbf{y} \text { is the vector of phenotypic observations, } \mathbf{b} \text { is the vector of fixed non-genetic }}$

494

495

496

497

498

499

500

501

502

503

504

505

506

507

508

509

510

511

512

513

effects and $\mathbf{X}$ is the design matrix relating fixed non-genetic effects to observations. $\mathbf{Z}$ is the

incidence matrix for random polygenic effects $\left(\mathbf{u} \sim \mathrm{N}\left(0, \mathbf{A} \sigma_{\underline{u}}{ }^{2}\right)\right.$-where $\mathbf{A}$ is the numerator

relationship matrix and $\sigma_{u}{ }^{2}$ is the polygenic variance)- and single locus effects. $\mathbf{W}$ is a three

column matrix that contains information on the genotype of each individual and $\mathrm{m}$ is the

vector of major-genotype means ( $\left.\mathbf{m}^{\prime}=[-\mathrm{a}, \mathrm{d}, \mathrm{a}]\right)$, hence $\mathbf{W m}$ is the vector of random effects

at the single locus. e $\left(\sim \mathrm{N}\left(0, \mathbf{I} \underline{\underline{e}}^{2}\right)\right)$ is a vector of random errors.

Janss et al. (1995) proposed an efficient scheme using the Gibbs sampler for the $\underline{\text { study of mixed inheritance models in animal populations. In our analyses, carried out with }}$ software developed at Roslin Institute by Ricardo Pong-Wong (Walling et al., 2002), we used the sampling scheme they described (see Janss et al. (1995) and Janss et al. (1997) for details) to obtain marginal posterior distributions for the major locus parameters (frequency and additive and dominance effect), population mean and polygenic and residual variances. For each iteration of the Gibbs sampler, every bird was assigned a genotype. Averaging over

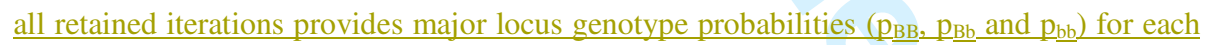
bird in the pedigree.

The variance explained by the major locus $\left(\sigma_{\underline{m}}{ }^{2}\right)$ is defined as:

$\underline{\sigma}_{\underline{m}}{ }^{2}=2 \underline{p}_{\underline{B}}\left(1-\underline{p_{B}}\right)\left[a+d\left(\left(1-\underline{p_{B}}\right)-\underline{p_{B}}\right)\right]^{2}+\left[2 \underline{p}_{\underline{B}}\left(1-\underline{p_{B}}\right) d\right]^{2}$

(Falconer and Mackay, 1996) and was computed from the major locus genotypic effects and allele frequency sampled at each iteration. Likewise, we calculated the degree of dominance as d/a. 
density at the global mode was 20 times larger than that at $\sigma_{\mathrm{m}}{ }^{2}=0$. We used the same criterion.

In order to ease computation, the segregation analyses were carried out using $\mathrm{SaO}$ phenotypes adjusted for the fixed effects of hatch week (210 and 133 levels respectively for data sets 1 and 2) and age of the dam at laying (10 and 9 levels respectively for data sets 1 and 2). Adjusted $\mathrm{SaO}$ phenotypes were obtained from trivariate analyses of $\mathrm{SaO}$, Weight and Flesh data, performed fitting an animal model within a Restricted Maximum Likelihood (REML) framework using ASREML (Gilmour et al., 2000). These analyses assumed that all three traits are under the genetic control of an infinite number of loci with small additive effects. If a major locus was involved in the genetic control of a trait, its segregation variance

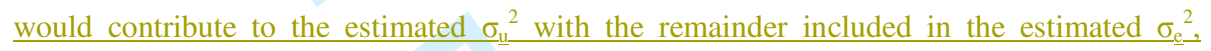
together with polygenic non-additive variance, since the infinitesimal model does not accommodate non-additive genetic variation (although it can be extended to do so) or changes in variance caused by changes in major locus allele frequency (Turelli and Barton, 1994). Only adjusted phenotypes from birds that originally had SaO records were used, but the pedigree included contemporary unrecorded birds. This allowed us to obtain genotype probabilities for all birds in the pedigree.

Analyses of Genotype Probabilities and Allele Frequencies. Some exploratory analyses were carried out on genotype probabilities obtained from data set 2 analyses. From each iteration of the Gibbs sampler, genotype configurations were obtained for all birds in the pedigree. Averaging over all retained iterations, probabilities of each bird being $\mathrm{BB}, \mathrm{Bb}$ or bb could be obtained. For each bird, as many sets of genotype probabilities as chains were produced and an overall estimate of each genotype probability was obtained by averaging the results from each chain. Genotypic frequencies at a given moment in time could be obtained by averaging the frequencies of birds in the chosen period and estimates of major allele

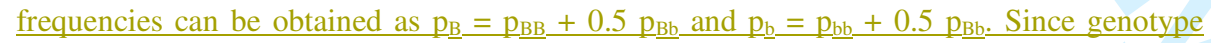
probability estimates are a function of the individual's phenotypic record and information 
from its relatives, we divided the population on the basis of the amount of information available for each individual in birds with no record, selection candidates and sires. Most of the results presented will be for the two last categories since accuracy of estimates should be highest for sires but using estimates from selection candidates as well one can attain a compromise between accuracy of estimates and sample size.

Estimation of the Putative Locus Effect on Weight and Fleshing Score. In order to investigate the effect of the putative major locus on body weight and fleshing score measured at five weeks of age, the phenotypic values for these traits were regressed on functions of the genotype probabilities estimated from the segregation analysis of data set 2.

The model used was:

with elements defined as in [1] and $\mathbf{c}, \mathbf{S}, \mathbf{g}$ and $\mathbf{R}$ are respectively the vector of random maternal environmental effects for Weight and Flesh and the design matrix relating maternal environmental effects to observations $\left(\mathbf{c} \sim \mathrm{N}\left(0, \mathbf{I} \underline{e m}^{2}\right)\right.$ and the vector of random maternal genetic effects for Weight and Flesh and the design matrix relating maternal environmental effects to observations $\left(\mathrm{g} \sim \mathrm{N}\left(0, \mathbf{A} \sigma_{\mathrm{gm}}{ }^{2}\right)\right.$. $\mathbf{X}$ now includes $\mathrm{c}_{\underline{a}}=\left(\mathrm{p}_{\underline{B} \mathrm{~B}}-\mathrm{p}_{\mathrm{bb}}\right)$ and $\underline{\mathrm{C}_{\mathrm{d}}}=\mathrm{p}_{\mathrm{Bb}}$, allowing one to estimate respectively the additive and the dominance effect of the putative locus on the traits. A trivariate analysis was carried out within a REML framework, fitting an animal model using ASREML (Gilmour et al., 2000).

\section{$\underline{\text { RESULTS }}$}

\section{Segregation Analyses}

For all runs and parameters, chains seemed to have converged to their equilibrium distributions after a 5000 iteration burn-in period and sample autocorrelation was generally low (absolute values smaller than 0.1) for lags over 100 for all parameters (results not shown). Marginal posterior distributions of all parameters were symmetric and approximated normal distributions. Table A1 shows the marginal posterior means, posterior standard deviations, Monte Carlo standard deviation of marginal posterior means and the effective 
number of samples per chain for all sampled parameters. The difference between marginal posterior means from the six chains ran for data set 1 was not always strictly within the Monte Carlo sampling error estimated as proposed by Geyer (1992). Nonetheless, all chains seemed to have converged to the equilibrium distribution (using different starting values) and marginal posterior means were very close. The effective number of samples was variable within chains between parameters and within parameters between chains, with values ranging from nine to more than 600 independent samples. Generally $\sigma_{\underline{u}}{ }^{2}$ and $\sigma_{\underline{e}}{ }^{2}$ showed smaller effective numbers of samples, which reflects poorer mixing for these parameters.

The visual inspection of the six chains did not show convergence problems. [TABLE A1]

$\underline{\text { Samples were pooled across chains and the means of the pooled distributions and }}$ their standard deviations were used as point estimates of the sampled parameters and their standard errors. Since the total number of independent samples for any parameter was greater than 100 , the mean and the standard deviation of the pooled posterior distribution were assumed to be good estimates of the parameter and its standard error. Table 4 shows point estimates of the parameters sampled and those derived and the standard deviation of $\underline{\text { their pooled posterior distributions. All distributions presented zero densities for parameter }}$ values equal to zero. Following Janss et al. (1995) we inferred that a locus with large effect on $\mathrm{SaO}$ was segregating in the population studied. Although the estimated d was slightly larger than a, estimated major locus effects were similar in size (the dominance deviance was estimated to be $1.12( \pm 0.06)$ and was indeed just different from one. We will assume in the following that a and d can be considered equal,

Analyses were repeated for data set 2, using raw phenotypes (records not adjusted for fixed effects) and sampling fixed effects (age of dam and hatch). These analyses yielded estimates of the parameters presented in table 4 that were similar to the ones obtained from
Formatted: Normal, Left, Line spacing: single 

adjusted phenotypes (results not shown), showing that, in this case, preadjustement of phenotypes did not have a significant effect on parameter estimates.

\section{DISCUSSION}

On Skewness

When a major locus is segregating, the population distribution of phenotypes can be $\underline{\text { skewed. MacLean et al. (1975) showed that skewness of the phenotypic distributions, when }}$ not caused by segregation of loci with large effect, could lead to detection of a spurious major locus. MacLean et al. (1976) suggested applying a transformation to the phenotypic data to remove skewness prior to analysis, but showed that this could considerably reduce the power to detect major genes when present, as well as posing problems for the interpretation of the results (Demenais et al., 1986). Using data set 2, we applied a transformation to $\mathrm{SaO}$ data, in order to obtain a trait distribution closer to a Normal. The transformation applied was $\mathrm{Ln}(100-\mathrm{SaO})$, and the transformed trait distribution had a skewness coefficient of -0.29 and a kurtosis coefficient of -0.17 . The heritability of $\operatorname{Ln}(100$ - $\mathrm{SaO}$ ) was 0.14 , which is almost identical to that obtained for untransformed data. The outcome of the analysis of transformed data was that a dominant locus with large effect on $\underline{\operatorname{Ln}(100-\mathrm{SaO})\left(\mathrm{a}=\mathrm{d}=0.58 \sigma_{\mathrm{p}}\right) \text { was segregating in this line, but neither the frequency nor the }}$ mode of action of this putative locus were in agreement with the results obtained from untransformed data. Indeed, an allele that increases $\mathrm{Ln}(100-\mathrm{SaO})$ would decrease $\mathrm{SaO}$, so the estimated $\mathrm{p}_{\mathrm{B}}=0.69$ from this analysis needs to be compared to $(1-0.65)=0.35$. In the same way, if the locus that increases $\operatorname{Ln}(100-\mathrm{SaO})$ were dominant, the proportion of birds showing low $\mathrm{SaO}$ values would be around $81 \%$ compared with the predicted $12 \%$ from the untransformed data analysis. Moreover, the correlation between the probability of a bird being heterozygote estimated from transformed and untransformed data was -0.17 ( $\mathrm{P}<$ $\underline{0.001)}$ for birds with $\mathrm{SaO}$ data and $-0.11(\mathrm{P}=0.03)$ for sires with $\mathrm{SaO}$ data. The fact that the estimates of $\mathrm{p}_{\mathrm{Bb}}$ are not similar from transformed and untransformed data suggests that these analyses are describing different phenomena. Selection experiments carried out in other 
broiler populations to study ascites susceptibility tend to suggest that this trait is influenced

647 by a single biallelic major locus that would act in a recessive fashion (see for example,

Druyan et al. (2001), Druyan et al. (2002), Wideman and French (1999) and Wideman and French (2000)). This would support the mode of action suggested for SaO by the analysis of untransformed data.

\section{On Variance Components Estimates (Simulation)}

We observed that, for the analyses carried out, the total additive variance estimated using a mixed inheritance model was greater than the additive variance estimated using a polygenic model. In order to assess whether this would be expected in the presence of a segregating major gene in a population under selection a simulation study was performed. 125 five-generation pedigrees (base population and four generations of random or phenotypic selection) were simulated with a structure chosen to resemble the (real) pedigree analyzed. In each generation, 40 males were mated to eight (different) females that produced $\underline{\text { three male and three female offspring each (i.e., population size was maintained constant). In }}$ the case of phenotypic selection, the 40 males and 320 females with highest phenotypes were selected to produce the next generation. The simulated pedigrees consisted in 9600 individuals. Phenotypes were assumed to be under the control of a gene with large effect and a large number of polygenes with small additive effect, as well as partially determined by the environment. The parameters used for the simulation were the ones presented in Table 4 for data set 2. Data from all animals or from males alone (to mimic our data structure) were analyzed assuming an infinitesimal model, within a REML framework, using ASREML (Gilmour et al., 2000). In a second stage, the pedigrees were analyzed assuming a mixed inheritance model (as described in the materials and methods section) and only data from males were used. Table A2 shows the means and standard deviations of the parameters estimated. In brief, the simulation study showed that, in a population in which both a major gene and polygenic variation are actually present and which is under phenotypic selection. the estimate of the total additive variance is severely biased downward if a purely polygenic 


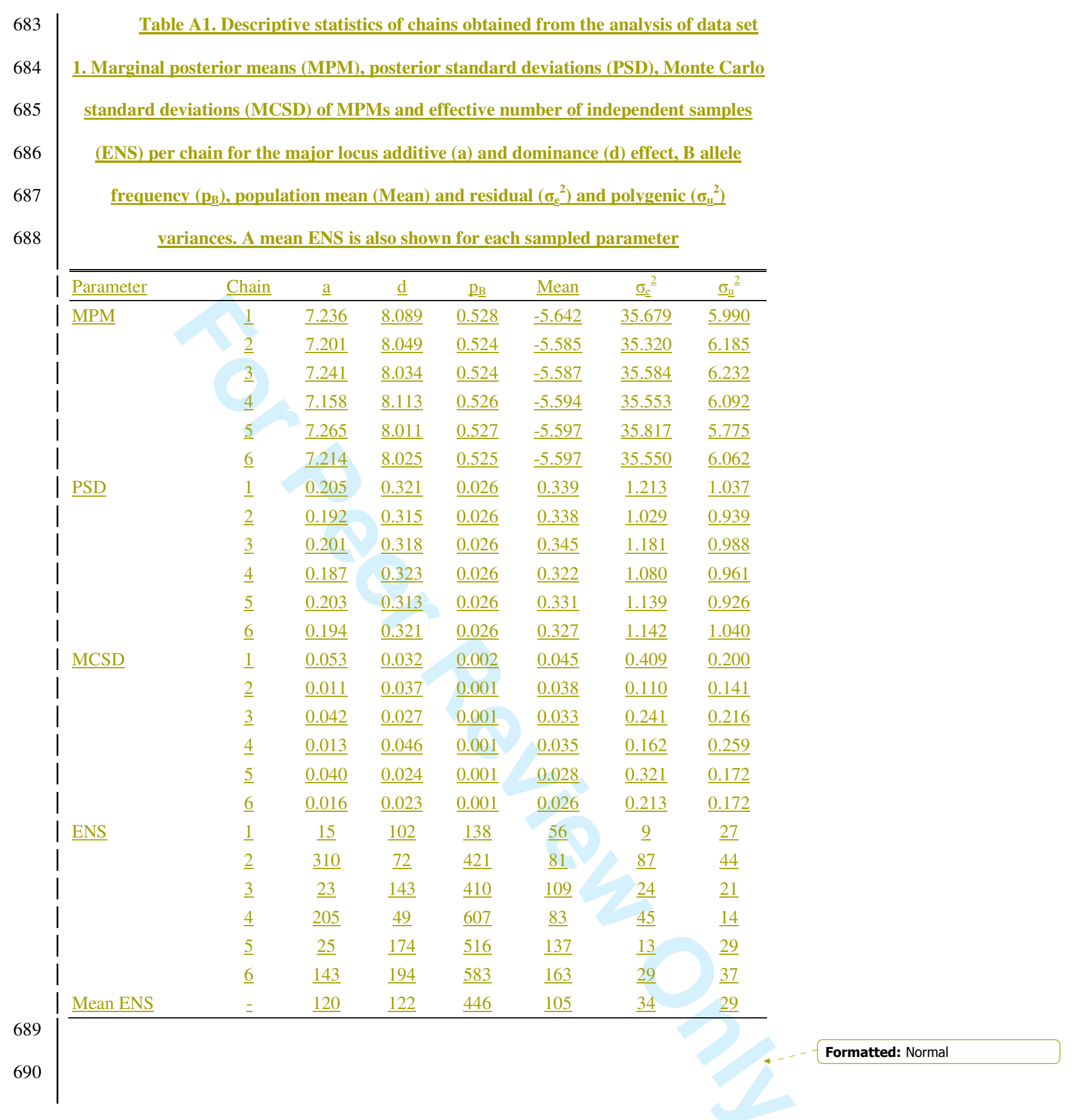




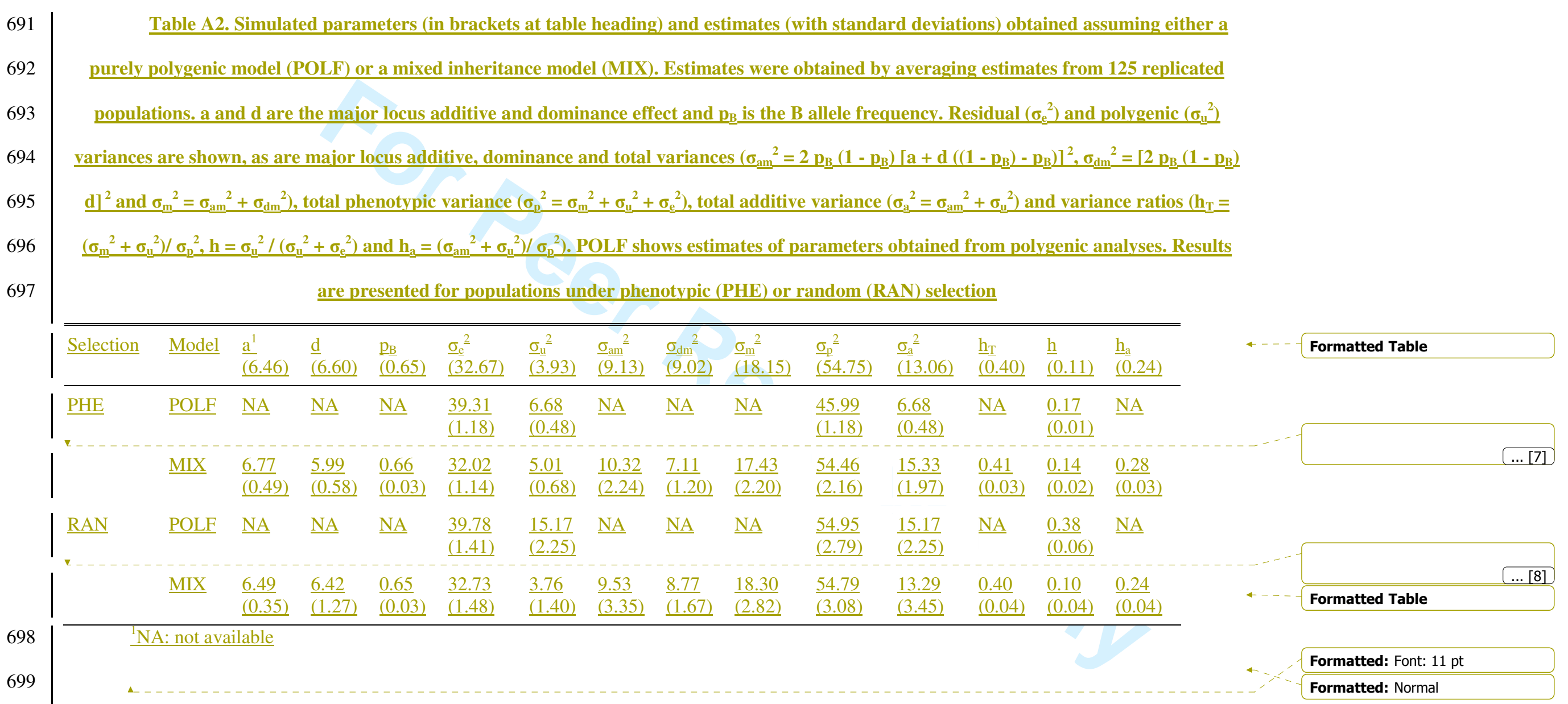




\section{Page 7: [1] Deleted}

The mixed model equation that describes the model fitted to the data is:

$\mathbf{y}=\mathbf{X b}+\mathbf{Z u}+\mathbf{Z W m}+\mathbf{e}$

where $\mathbf{y}$ is the vector of phenotypic observations, $\mathbf{b}$ is the vector of fixed non-genetic effects and $\mathbf{X}$ is the design matrix relating fixed non-genetic effects to

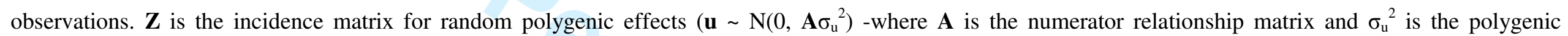

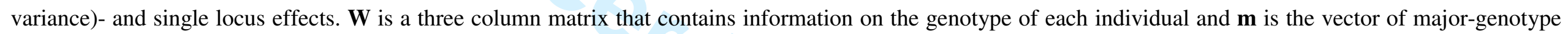
means $\left(\mathbf{m}^{\prime}=[-\mathrm{a}, \mathrm{d}, \mathrm{a}]\right)$, hence $\mathbf{W m}$ is the vector of random effects at the single locus. $\mathbf{e}\left(\sim \mathrm{N}\left(0, \mathbf{I} \sigma_{\mathrm{e}}{ }^{2}\right)\right)$ is a vector of random errors.

Janss et al. (1995) proposed an efficient scheme using the Gibbs sampler for the study of mixed inheritance models in animal populations. In our analyses,

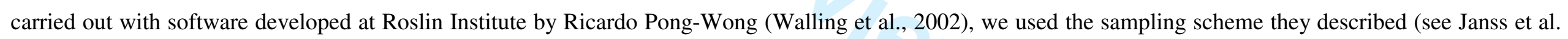

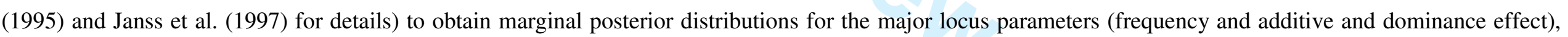

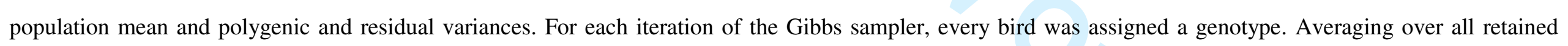
iterations provides major locus genotype probabilities $\left(\mathrm{p}_{\mathrm{BB}}, \mathrm{p}_{\mathrm{Bb}}\right.$ and $\left.\mathrm{p}_{\mathrm{bb}}\right)$ for each bird in the pedigree.

The variance explained by the major locus $\left(\sigma_{\mathrm{m}}{ }^{2}\right)$ is defined as:

$\sigma_{m}^{2}=2 p_{B}\left(1-p_{B}\right)\left[a+d\left(\left(1-p_{B}\right)-p_{B}\right)\right]^{2}+\left[2 p_{B}\left(1-p_{B}\right) d\right]^{2}$

(Falconer and Mackay, 1996) and was computed from the major locus genotypic effects and allele frequency sampled at each iteration. Likewise, we calculated the degree of dominance as $d / a$. 
We used non-informative prior distributions, uniform on $(-\infty ;+\infty)$ for fixed non-genetic effects and $\mathrm{d}$, on $[0 ;+\infty)$ for a and on $[0 ; 1]$ for major allele B frequency. We used an inverse-gamma prior distribution on $(0 ;+\infty)$ for variances with a flat prior for $\log ($ variance). This type of prior distribution for variances 19 should cause the mean of the marginal posterior distributions to tend towards zero if the data available do not support variation of the random effects. All genotypes were initialized as Bb.

Six runs of the Gibbs sampler were carried out for the analysis of each data set, with different starting values. Differences in parameter estimates obtained from different chains may reflect problems of mixing. Individual chains were composed by 255000 iterations that were collected after allowing for a burn-in period of 5000 iterations, keeping each $100^{\text {th }}$ iteration from this point onwards. In order to assess if the burn-in period and thinning parameter we used were adequate, we studied the marginal posterior distributions of the sampled parameters obtained from each run of the Gibbs sampler. For data set 1 analyses, the marginal posterior means, that is the parameter's a-posteriori expectation, the posterior standard deviations and the Monte Carlo standard deviations are reported. The Monte Carlo standard deviation of the marginal posterior mean was computed following Geyer (1992) as suggested by Sorensen et al. (1995) and the effective number of samples per chain, i.e. the number of independent samples per chain for each parameter, was estimated. Following the results obtained when studying the behaviour of the individual chains for data set 1 , no formal assessment of convergence was carried out for data set 2 analyses, but a visual inspection of individual chains was carried out for each of the analyses. After studying individual chains, the samples were pooled across chains and the mean of the pooled distribution and its standard deviation were used as summary statistics. Janss et al. (1995) suggested the use of the ratio of the density at $\sigma_{\mathrm{m}}{ }^{2}=0$ of the marginal posterior distribution of $\sigma_{\mathrm{m}}{ }^{2}$ and the density at the global mode as a criterion to test the significance of the single locus component. They inferred the presence of a single locus $(0.05$ significance level) if the density at the global mode was 20 times larger than that at $\sigma_{\mathrm{m}}{ }^{2}=0$. We used the same criterion. 
In order to ease computation, the segregation analyses were carried out using SaO phenotypes adjusted for the fixed effects of hatch week (210 and 133

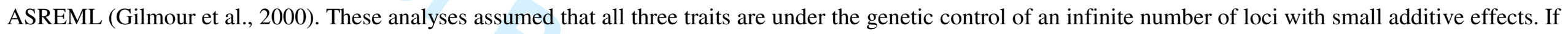

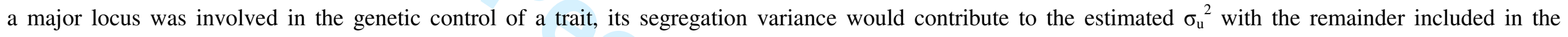

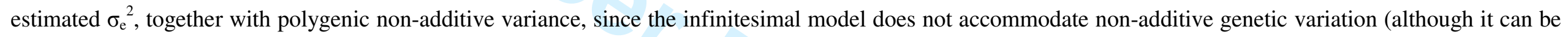

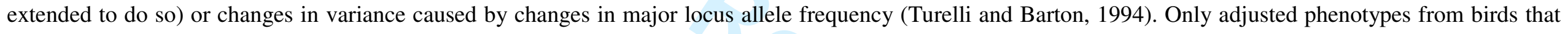

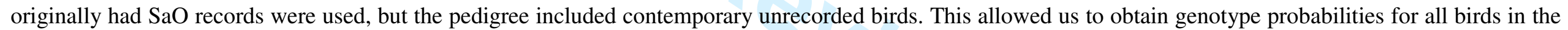
pedigree.

Analyses of Genotype Probabilities and Allele Frequencies. Some exploratory analyses were carried out on genotype probabilities obtained from data set 2

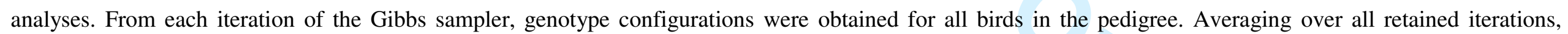

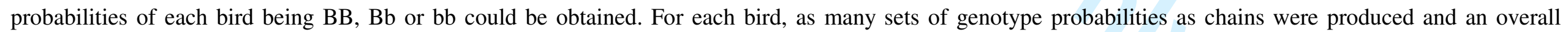

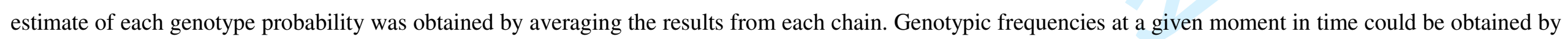

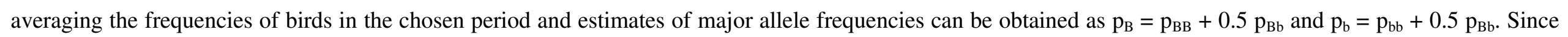

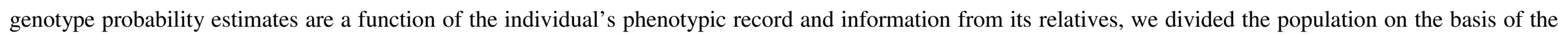

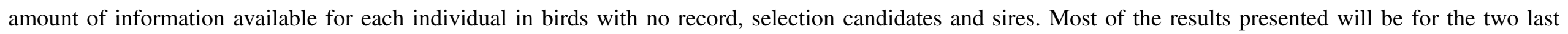


categories since accuracy of estimates should be highest for sires but using estimates from selection candidates as well one can attain a compromise between accuracy of estimates and sample size.

Estimation of the Putative Locus Effect on Weight and Fleshing Score. In order to investigate the effect of the putative major locus on body weight and fleshing score measured at five weeks of age, the phenotypic values for these traits were regressed on functions of the genotype probabilities estimated from the segregation analysis of data set 2 . The model used was:

$$
\mathbf{y}=\mathbf{X b}+\mathbf{Z u}+\mathbf{S c}+\mathbf{R g}+\mathbf{e}
$$

with elements defined as in [1] and $\mathbf{c}, \mathbf{S}, \mathbf{g}$ and $\mathbf{R}$ are respectively the vector of random maternal environmental effects for Weight and Flesh and the design matrix relating maternal environmental effects to observations $\left(\mathbf{c} \sim \mathrm{N}\left(0, \mathbf{I} \sigma_{\mathrm{em}}{ }^{2}\right)\right.$ and the vector of random maternal genetic effects for Weight and Flesh and the design matrix relating maternal environmental effects to observations $\left(\mathbf{g} \sim \mathrm{N}\left(0, \mathbf{A} \sigma_{\mathrm{gm}}{ }^{2}\right)\right.$. $\mathbf{X}$ now includes $\mathrm{c}_{\mathrm{a}}=\left(\mathrm{p}_{\mathrm{BB}}-\mathrm{p}_{\mathrm{bb}}\right)$ and $\mathrm{c}_{\mathrm{d}}=\mathrm{p}_{\mathrm{Bb}}$, allowing one to estimate respectively the additive and the dominance effect of the putative locus on the traits. A trivariate analysis was carried out within a REML framework, fitting an animal model using ASREML (Gilmour et al., 2000).

Page 8: [2] Deleted

pau

3/7/2006 11:37:00 AM

shows point estimates of the parameters sampled and those derived and the standard deviation of their pooled posterior distributions. All distributions presented zero densities for parameter values equal to zero. Following Janss et al. (1995) we inferred that a locus with large effect on SaO was segregating in the population studied. 
MacLean et al. (1976) suggested applying a transformation to the phenotypic data to remove skewness prior to analysis, but showed that this could

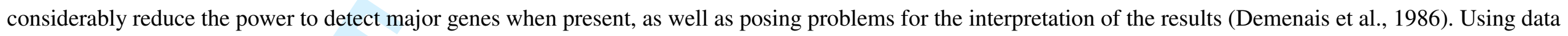

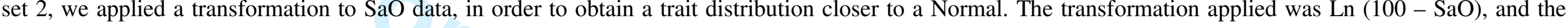

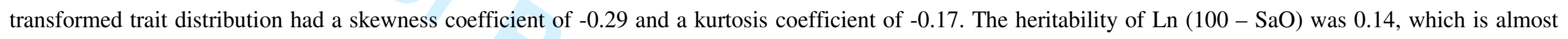

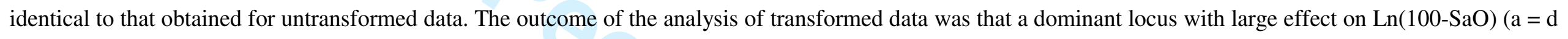

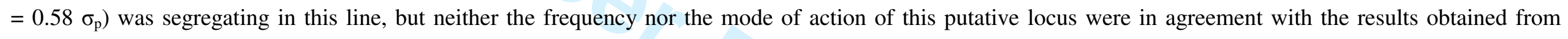

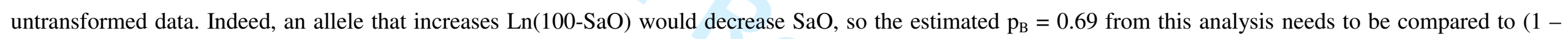

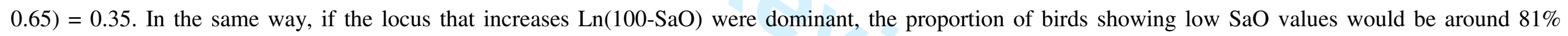

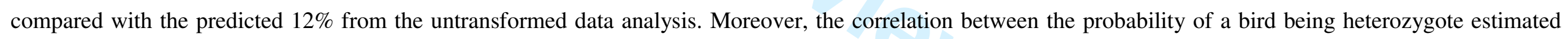

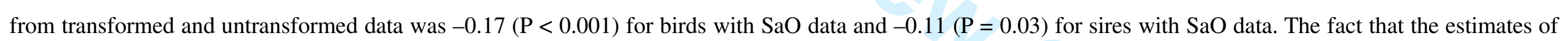

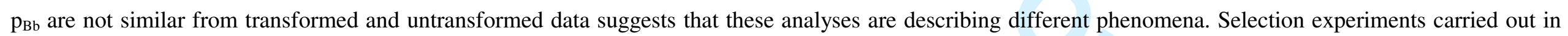

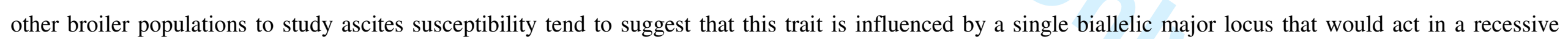

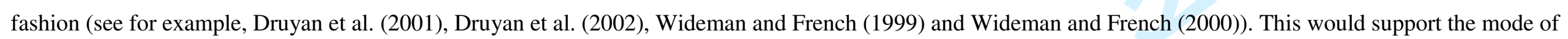
action suggested for $\mathrm{SaO}$ by the analysis of untransformed data.

We observed that, for the analyses carried out, the total additive variance estimated using a mixed inheritance model was greater than the additive variance

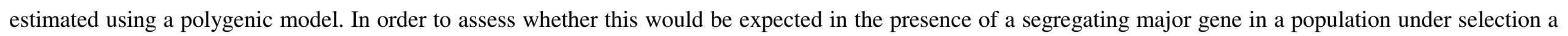

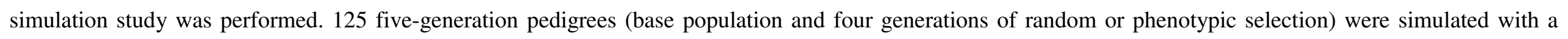


84 structure chosen to resemble the (real) pedigree analyzed. In each generation, 40 males were mated to eight (different) females that produced three male and three 85 female offspring each (i.e., population size was maintained constant). In the case of phenotypic selection, the 40 males and 320 females with highest phenotypes 86 were selected to produce the next generation. The simulated pedigrees consisted in 9600 individuals. Phenotypes were assumed to be under the control of a gene 87 with large effect and a large number of polygenes with small additive effect, as well as partially determined by the environment. The parameters used for the 88 simulation were the ones presented in Table 6 for data set 2. Data from all animals or from males alone (to mimic our data structure) were analyzed assuming an 89 infinitesimal model, within a REML framework, using ASREML (Gilmour et al., 2000). In a second stage, the pedigrees were analyzed assuming a mixed 90 inheritance model (as described in the materials and methods section) and only data from males were used. Table 8 shows the means and standard deviations of the 91 parameters estimated. In brief, the simulation study showed that, in a population in which both a major gene and polygenic variation are actually present and which 92 is under phenotypic selection, the estimate of the total additive variance is severely biased downward if a purely polygenic model is assumed. Estimates from REML 93 of additive variances obtained by simulation are in close agreement with results obtained when analyzing real data. Assuming a change in major allele frequencies 94 like the one shown in Figure 4 for selection candidates, we estimated that total additive variance would be underestimated by around $22 \%$ when assuming a purely 95 polygenic model. Results from simulation show that this underestimation is around $31 \%$. This, together with the fact that total additive variance seems to be well estimated (only slightly overestimated) under random selection, both assuming purely polygenic or mixed inheritance, would support the hypothesis that changes in allele frequencies caused by selection are the source of the observed discrepancies.

[TABLE 8] 
Table 5. Descriptive statistics of chains obtained from the analysis of data set 1. Marginal posterior means (MPM), posterior standard deviations

(PSD), Monte Carlo standard deviations (MCSD) of MPMs and effective number of independent samples (ENS) per chain for the major locus additive (a) and dominance $(d)$ effect, B allele frequency $\left(p_{B}\right)$, population mean (Mean) and residual $\left(\sigma_{\mathrm{e}}{ }^{2}\right)$ and polygenic $\left(\sigma_{\mathrm{u}}{ }^{2}\right)$ variances. A mean ENS is also shown for each sampled parameter

\begin{tabular}{lccccccc}
\hline \hline Parameter & Chain & $\mathrm{a}$ & $\mathrm{d}$ & $\mathrm{p}_{\mathrm{B}}$ & Mean & $\sigma_{\mathrm{e}}{ }^{2}$ & $\sigma_{\mathrm{u}}{ }^{2}$ \\
\hline MPM & 1 & 7.236 & 8.089 & 0.528 & -5.642 & 35.679 & 5.990 \\
& 2 & 7.201 & 8.049 & 0.524 & -5.585 & 35.320 & 6.185 \\
& 3 & 7.241 & 8.034 & 0.524 & -5.587 & 35.584 & 6.232 \\
& 4 & 7.158 & 8.113 & 0.526 & -5.594 & 35.553 & 6.092 \\
& 5 & 7.265 & 8.011 & 0.527 & -5.597 & 35.817 & 5.775 \\
PSD & 6 & 7.214 & 8.025 & 0.525 & -5.597 & 35.550 & 6.062 \\
& 1 & 0.205 & 0.321 & 0.026 & 0.339 & 1.213 & 1.037 \\
& 2 & 0.192 & 0.315 & 0.026 & 0.338 & 1.029 & 0.939 \\
& 3 & 0.201 & 0.318 & 0.026 & 0.345 & 1.181 & 0.988 \\
& 4 & 0.187 & 0.323 & 0.026 & 0.322 & 1.080 & 0.961 \\
MCSD & 5 & 0.203 & 0.313 & 0.026 & 0.331 & 1.139 & 0.926 \\
& 6 & 0.194 & 0.321 & 0.026 & 0.327 & 1.142 & 1.040 \\
& 1 & 0.053 & 0.032 & 0.002 & 0.045 & 0.409 & 0.200 \\
& 2 & 0.011 & 0.037 & 0.001 & 0.038 & 0.110 & 0.141 \\
& 3 & 0.042 & 0.027 & 0.001 & 0.033 & 0.241 & 0.216 \\
& 4 & 0.013 & 0.046 & 0.001 & 0.035 & 0.162 & 0.259 \\
& 5 & 0.040 & 0.024 & 0.001 & 0.028 & 0.321 & 0.172
\end{tabular}




\begin{tabular}{lccccccc}
\multirow{2}{*}{ ENS } & 6 & 0.016 & 0.023 & 0.001 & 0.026 & 0.213 & 0.172 \\
& 1 & 15 & 102 & 138 & 56 & 9 & 27 \\
& 2 & 310 & 72 & 421 & 81 & 87 & 44 \\
& 3 & 23 & 143 & 410 & 109 & 24 & 21 \\
& 4 & 205 & 49 & 607 & 83 & 45 & 14 \\
Mean ENS & 5 & 25 & 174 & 516 & 137 & 13 & 29 \\
\hline
\end{tabular}

Page 21: [5] Deleted

pau

3/5/2006 11:19:00 AM

Table 4. REML estimates of genetic $\left(\sigma_{\mathrm{u}}{ }^{2}\right)$, residual $\left(\sigma_{\mathrm{e}}{ }^{2}\right)$ and phenotypic $\left(\sigma_{\mathrm{p}}{ }^{2}\right)$ variances obtained for blood oxygen saturation for both data sets studied

\begin{tabular}{lccc}
\hline Data set & $\sigma_{\mathrm{u}}{ }^{2}$ & $\sigma_{\mathrm{e}}{ }^{2}$ & $\sigma_{\mathrm{p}}{ }^{2}$ \\
\hline 1 & 14.37 & 54.06 & 68.43 \\
2 & 8.18 & 45.18 & 53.36 \\
\hline
\end{tabular}

Page 24: [6] Deleted

pau

3/1/2006 3:56:00 PM

Table 8. Simulated parameters (in brackets at table heading) and estimates (with standard deviations) obtained assuming either a purely polygenic model (POL and POLF) or a mixed inheritance model (MIX). Estimates were obtained by averaging estimates from 125 replicated populations. a and d are the major locus additive and dominance effect and $p_{B}$ is the $B$ allele frequency. Residual $\left(\sigma_{\mathrm{e}}{ }^{2}\right)$ and polygenic $\left(\sigma_{\mathrm{u}}{ }^{2}\right)$ variances are shown, as are major locus 
additive, dominance and total variances $\left(\sigma_{\mathrm{am}}^{2}=2 \mathrm{p}_{\mathrm{B}}\left(1-\mathrm{p}_{\mathrm{B}}\right)\left[\mathrm{a}+\mathrm{d}\left(\left(1-\mathrm{p}_{\mathrm{B}}\right)-\mathrm{p}_{\mathrm{B}}\right)\right]^{2},{\sigma_{\mathrm{dm}}}^{2}=\left[2 \mathrm{p}_{\mathrm{B}}\left(1-\mathrm{p}_{\mathrm{B}}\right) \mathrm{d}\right]^{2}\right.$ and ${\sigma_{\mathrm{m}}}^{2}={\sigma_{\mathrm{am}}}^{2}+{\sigma_{\mathrm{dm}}}^{2})$, total phenotypic variance $\left(\sigma_{\mathrm{p}}{ }^{2}=\sigma_{\mathrm{m}}{ }^{2}+{\sigma_{\mathrm{u}}}^{2}+\sigma_{\mathrm{e}}{ }^{2}\right)$, total additive variance $\left(\sigma_{\mathrm{a}}{ }^{2}=\sigma_{\mathrm{am}}{ }^{2}+\sigma_{\mathrm{u}}{ }^{2}\right)$ and variance ratios $\left(\mathrm{h}_{\mathrm{T}}=\left(\sigma_{\mathrm{m}}{ }^{2}+\sigma_{\mathrm{u}}{ }^{2}\right) / \sigma_{\mathrm{p}}{ }^{2}, \mathrm{~h}=\sigma_{\mathrm{u}}{ }^{2} /\left(\sigma_{\mathrm{u}}{ }^{2}+{\sigma_{\mathrm{e}}}^{2}\right)\right.$ and $\left.\mathrm{h}_{\mathrm{a}}=\left(\sigma_{\mathrm{am}}{ }^{2}+\sigma_{\mathrm{u}}{ }^{2}\right) / \sigma_{\mathrm{p}}{ }^{2}\right)$. POLF and POL show estimates of parameters obtained from polygenic analyses before and after censoring female phenotypes. Results are presented for populations under phenotypic (PHE) or random (RAN) selection

\begin{tabular}{|c|c|c|c|c|c|c|c|c|c|c|c|c|c|c|}
\hline Selection & Model & $\begin{array}{l}\mathrm{a}^{1} \\
(6.46)\end{array}$ & $\begin{array}{l}\mathrm{d} \\
(6.60)\end{array}$ & $\begin{array}{l}\mathrm{p}_{\mathrm{B}} \\
(0.65)\end{array}$ & $\begin{array}{l}\sigma_{\mathrm{e}}^{2} \\
(32.67)\end{array}$ & $\begin{array}{l}\sigma_{\mathrm{u}}^{2} \\
(3.93)\end{array}$ & $\begin{array}{l}\sigma_{a m}^{2} \\
(9.13)\end{array}$ & $\begin{array}{l}\sigma_{\mathrm{dm}}^{2} \\
(9.02)\end{array}$ & $\begin{array}{l}\sigma_{\mathrm{m}}^{2} \\
(18.15)\end{array}$ & $\begin{array}{l}\sigma_{\mathrm{p}}^{2} \\
(54.75)\end{array}$ & $\begin{array}{l}\sigma_{\mathrm{a}}^{2} \\
(13.06)\end{array}$ & $\begin{array}{l}\mathrm{h}_{\mathrm{T}} \\
(0.40)\end{array}$ & $\begin{array}{l}\mathrm{h} \\
(0.11)\end{array}$ & $\begin{array}{l}\mathrm{h}_{\mathrm{a}} \\
(0.24)\end{array}$ \\
\hline \multirow[t]{3}{*}{ PHE } & POLF & NA & NA & NA & $\begin{array}{l}39.31 \\
(1.18)\end{array}$ & $\begin{array}{l}6.68 \\
(0.48)\end{array}$ & NA & NA & NA & $\begin{array}{l}45.99 \\
(1.18)\end{array}$ & $\begin{array}{l}6.68 \\
(0.48)\end{array}$ & NA & $\begin{array}{l}0.17 \\
(0.01)\end{array}$ & NA \\
\hline & POL & NA & NA & NA & $\begin{array}{l}37.38 \\
(1.42)\end{array}$ & $\begin{array}{l}8.94 \\
(0.79)\end{array}$ & NA & NA & NA & $\begin{array}{l}46.32 \\
(1.36)\end{array}$ & $\begin{array}{l}8.94 \\
(0.79)\end{array}$ & NA & $\begin{array}{l}0.24 \\
(0.03)\end{array}$ & NA \\
\hline & MIX & $\begin{array}{l}6.77 \\
(0.49)\end{array}$ & $\begin{array}{l}5.99 \\
(0.58)\end{array}$ & $\begin{array}{l}0.66 \\
(0.03)\end{array}$ & $\begin{array}{l}32.02 \\
(1.14)\end{array}$ & $\begin{array}{l}5.01 \\
(0.68)\end{array}$ & $\begin{array}{l}10.32 \\
(2.24)\end{array}$ & $\begin{array}{l}7.11 \\
(1.20)\end{array}$ & $\begin{array}{l}17.43 \\
(2.20)\end{array}$ & $\begin{array}{l}54.46 \\
(2.16)\end{array}$ & $\begin{array}{l}15.33 \\
(1.97)\end{array}$ & $\begin{array}{l}0.41 \\
(0.03)\end{array}$ & $\begin{array}{l}0.14 \\
(0.02)\end{array}$ & $\begin{array}{l}0.28 \\
(0.03)\end{array}$ \\
\hline \multirow[t]{3}{*}{ RAN } & POLF & NA & NA & NA & $\begin{array}{l}39.78 \\
(1.41)\end{array}$ & $\begin{array}{l}15.17 \\
(2.25)\end{array}$ & NA & NA & NA & $\begin{array}{l}54.95 \\
(2.79)\end{array}$ & $\begin{array}{l}15.17 \\
(2.25)\end{array}$ & NA & $\begin{array}{l}0.38 \\
(0.06)\end{array}$ & NA \\
\hline & POL & NA & NA & NA & $\begin{array}{l}39.63 \\
(2.02)\end{array}$ & $\begin{array}{l}15.24 \\
(3.04)\end{array}$ & NA & NA & NA & $\begin{array}{l}54.87 \\
(3.01)\end{array}$ & $\begin{array}{l}15.24 \\
(3.04)\end{array}$ & NA & $\begin{array}{l}0.39 \\
(0.09)\end{array}$ & NA \\
\hline & MIX & $\begin{array}{l}6.49 \\
(0.35)\end{array}$ & $\begin{array}{l}6.42 \\
(1.27)\end{array}$ & $\begin{array}{l}0.65 \\
(0.03)\end{array}$ & $\begin{array}{l}32.73 \\
(1.48)\end{array}$ & $\begin{array}{l}3.76 \\
(1.40)\end{array}$ & $\begin{array}{l}9.53 \\
(3.35)\end{array}$ & $\begin{array}{l}8.77 \\
(1.67)\end{array}$ & $\begin{array}{l}18.30 \\
(2.82)\end{array}$ & $\begin{array}{l}54.79 \\
(3.08)\end{array}$ & $\begin{array}{l}13.29 \\
(3.45)\end{array}$ & $\begin{array}{l}0.40 \\
(0.04)\end{array}$ & $\begin{array}{l}0.10 \\
(0.04)\end{array}$ & $\begin{array}{l}0.24 \\
(0.04)\end{array}$ \\
\hline
\end{tabular}

${ }^{1}$ NA: not available 


\begin{tabular}{cccccccccccc} 
Page 43: [7] Deleted & \multicolumn{10}{c}{ pau } & \multicolumn{8}{c}{$\mathbf{3 / 5 / 2 0 0 6}$ 11:27:00 AM } \\
POL & NA & NA & NA & $\begin{array}{l}37.38 \\
(1.42)\end{array}$ & $\begin{array}{l}8.94 \\
(0.79)\end{array}$ & NA & NA & NA & 46.32 & 8.94 \\
& & & & & & & $(1.36)$ & $(0.79)$
\end{tabular}

Page 43: [8] Deleted pau 3/5/2006 11:28:00 AM

$\begin{array}{llllllllll}\text { POL NA NA } & \text { NA } & 39.63 & 15.24 & \text { NA } & \text { NA } & \text { NA } & 54.87 & 15.24\end{array}$

(2.02) (3.04) (3.01) (3.04)

E-mail: br.poultsci@bbsrc.ac.uk URL: http://mc.manuscriptcentral.com/cbps 